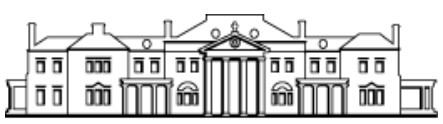

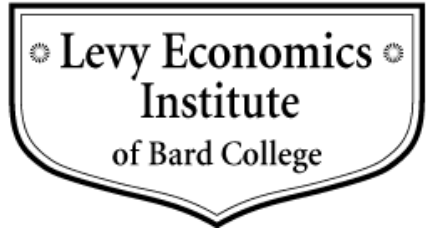

Working Paper No. 958

\title{
A Stock-Flow Consistent Quarterly Model of the Italian Economy
}

\author{
by \\ Francesco Zezza* \\ Levy Economics Institute of Bard College \\ and \\ Università degli Studi del Sannio \\ and \\ Gennaro Zezza \\ Levy Economics Institute of Bard College \\ and \\ Università degli Studi di Cassino
}

June 2020

\begin{abstract}
* The model presented here is an evolution of the one presented in F. Zezza (2018). We wish to thank Eugenio Caverzasi, Riccardo De Bonis, Antoine Godin, Roberto Golinelli, Eckhard Hein, Jan Kregel, Dany Lang, Marc Lavoie, Michalis Nikiforos, Ernesto Screpanti, Alessandro Vercelli, and Marco Veronese Passarella for useful suggestions or comments to previous versions of this work.

The Levy Economics Institute Working Paper Collection presents research in progress by Levy Institute scholars and conference participants. The purpose of the series is to disseminate ideas to and elicit comments from academics and professionals.
\end{abstract}

Levy Economics Institute of Bard College, founded in 1986, is a nonprofit, nonpartisan, independently funded research organization devoted to public service. Through scholarship and economic research it generates viable, effective public policy responses to important economic problems that profoundly affect the quality of life in the United States and abroad.

Levy Economics Institute

P.O. Box 5000

Annandale-on-Hudson, NY 12504-5000

http://www.levyinstitute.org

Copyright (C) Levy Economics Institute 2020 All rights reserved

ISSN 1547-366X 


\begin{abstract}
Macroeconomists and political officers need rigorous, albeit realistic, quantitative models to forecast the future paths and dynamics of some variables of interest while being able to evaluate the effects of alternative scenarios. At the heart of all these models lies a standard macroeconomic module that, depending on the degree of sophistication and the research questions to be answered, represents how the economy works. However, the complete absence of a realistic monetary framework, along with the abstraction of banks and more generally of real-financial interactions - not only in dynamic stochastic general equilibrium (DSGE) models but also in central banks' structural econometric models — made it impossible to detect the rising financial fragility that led to the Great Recession.
\end{abstract}

In this paper, we show how to address the missing links between the real and financial sectors within a post-Keynesian framework, presenting a quarterly stock-flow consistent (SFC) structural model of the Italian economy. We set up the accounting structure of the sectoral transactions, describing our "transaction matrix" and "balance sheet matrix," starting from the appropriate sectoral data sources. We then "close" all sectoral financial accounts, describe portfolio choices, and define the buffer stocks for each class of assets and sector in the model. We describe our estimation strategy, present the main stochastic equations, and, finally, discuss the main channels of transmissions in our model.

KEYWORDS: Empirical Stock-Flow Consistent Models; Monetary Policy; Italy

JEL CLASSIFICATIONS: C54; E12; E17; E44; E58 


\section{INTRODUCTION}

Macroeconomists and policymakers need rigorous, albeit realistic, quantitative models to track the future paths and dynamics of some variables of interest, as well as to evaluate the effects of specific policies or external shocks. Research centers, government agencies, banks, unions, and others make use of econometric models tailored at answering different questions relative to their focus of interest. However, at the heart of all these models lies a standard macroeconomic module which, depending on the degree of sophistication and the research questions to be answer, represents how the economy works.

After the stagflation of the 1970s, "structural" models, developed following the Cowles Commission approach (Fair 2012), were abandoned by most central banks in favor of either dynamic stochastic general equilibrium (DSGE) types or micro-founded versions of investment-savings and liquidity preference-money supply (IS-LM) New-Keynesian models (Hendry and Muellbauer 2018). It is now widely accepted that the models used in policymaking agencies have performed poorly, to say the least, in detecting the last two major recessions (2000-1 and 2007-08). The complete absence of a realistic monetary framework, along with the abstraction of banks and more generally of real-financial interactions, not only in DSGE but also in central banks' structural econometric models, made it impossible to detect the rising financial fragility that led to the Great Recession. On the contrary, research groups adopting modeling approaches that considered the flow of funds of institutional sectors, and possibly the interrelation of balance sheets with saving and investment decisions, have been acknowledged for producing timely projections of the crises (Bezemer 2010).

In this paper, we present a quarterly stock-flow consistent (SFC) structural model of the Italian economy, developed within the SFC modeling approach pioneered by Wynne Godley (Godley and Lavoie 2007; Lavoie and Zezza 2011), which addresses the missing links between the real and financial sectors within a post-Keynesian framework. Our model follows the tradition of empirical SFC models developed by Godley and associates at the Levy Economics Institute of Bard College (Godley 1999; Papadimitriou, Nikiforos, and Zezza 2013); it does not follow the New Cambridge approach, which considers a three-sector economy, but expands the analysis of the private sector considering separately the interaction between households, nonfinancial corporations (NFCs), financial businesses, and the central bank. 
First, after a brief review of the existing models for the Italian economy, in section 2 we set up the accounting structure of the sectoral transactions, described in the "transaction" and "balance sheet" matrices. Then, in section 3, we present our "closures," describing the behavior of each institutional sector. We close the paper with a brief overview of the main channels of transmissions in the model.

\section{STRUCTURAL MODELS FOR THE ITALIAN ECONOMY}

Originally developed in the mid-1980s by a team from the Bank of Italy's (BoI) research department led by Albert Ando (Visco and Bodo 1986), the Bank of Italy Quarterly Model (BIQM) is continuously updated and evolves to capture the new features (i.e., changed institutional frameworks, policy rules, expectation formation mechanisms, etc.) of the system and data sources, and is still the BoI's main running tool for medium-term policy analysis.

As with most central banks' macro econometric models, the BIQM ${ }^{1}$ is $(\mathrm{New})$ Keynesian in the short run (with the level of economic activity primarily determined by the behavior of aggregate demand) and neoclassical in the long run (akin to Solow's model of exogenous growth). Thus, while in a steadystate growth path the dynamics of the model stem solely from capital accumulation, productivity growth, foreign demand, inflation, and demographics, in the short run there are several additional features (i.e., stickiness of prices and wages, the putty-clay nature of the production process, inflation surprises, etc.). The model, which makes use of survey data pertaining to expectation formation, is made up of some 900 equations of which some 100 are stochastic and estimated by means of limited information techniques, primarily ordinary least squares (OLS).

Another central bank model is the Italian block of the European Central Bank's (ECB) Multi-Country Model (MCM) (Angelini, D’Agostino, and McAdam 2006). The Italian MCM, being part of the bigger Area-Wide Model (AWM), closely follows the specifications and accounting structures of the AWM and of other MCM blocks. It is a quarterly structural macro model that treats the economy as relatively closed. As for the BIQM, it is demand-led in the short run, but fully supply-led in the long run, with a vertical Phillips curve and employment converging to an exogenously given non-accelerating inflation

\footnotetext{
${ }^{1}$ The latest model update is in Bulligan et al. (2017). A detailed description of the main features of the model can be found in Galli, Terlizzese, and Visco (1989).
} 
rate of unemployment (NAIRU). Stock-flow adjustments are accounted for, in a limited way, by the interactions between the stock of capital and the level of output and investment, and the impact of an exogenously given stock of financial wealth on consumption. The model has some 130 equations, of which about 20 are estimated by means of cointegration analysis.

Several other models have been developed by research departments and public institutions. Among the most important is the Italian Treasury Econometric Model (ITEM), developed by the Treasury Department of the Ministry of Economics and Finance (Cicinelli et al. 2008). It is a medium-size structural model consisting of some 300 variables and 250 equations/accounting identities of which about 30 are behavioral equations. It is estimated quarterly using national accounts data and it is used for projections and evaluations of domestic economic policies and changes in external/exogenous variables. As for the central bank models analyzed above, ITEM also belongs to the class of macroeconomic models that assign a prominent role to the supply side of the economy, with frictions in wages and price settings only (relatively) affecting demand in the short run.

We next find the MeMo-It model developed by Istituto Nazionale di Statistica (ISTAT) (Bacchini et al. 2013a; Bacchini et al. 2013b). This model, which is one of the three main tools used by ISTAT for its economic projections, makes use of global economic indicators and microsimulation models, together with current domestic economic indicators to forecast short-run scenarios for the main aggregates of the national accounts. While it is relatively simple in terms of its real-financial connections, it is worth noting the recent efforts to include an "environment" block in the model structure to capture links between economic and environmental variables, such as use of natural resources, pollution, etc.

Finally, there are a number of models run by think thanks such as, among others, the CSC model by the Italian employers' federation Confindustria (Pappalardo, Rapacciuolo, and Ruocco 2007), the PROMETEIA model by the privately run research center Prometeia (Welfe 2013), and the annual model developed by a/simmetrie (Bagnai and Mongeau Ospina 2014).

We do not aim at providing a deep theoretical and methodological discussion here, but a few remarks that pertain to all models cited above are needed. The following quote that, albeit pertaining to the BIQM, fits for all other models reviewed, is useful: "In equilibrium, [...] the BIQM describes a full employment economy, in which output, employment and the capital stock are consistent with an 
aggregate production function, relative prices are constant, and inflation equals the exogenous rate of growth of foreign prices. Money is neutral, though not super-neutral, and the model is stable (Busetti, Locarno, and Monteforte 2005: emphasis added).

One of the shortcomings of the approach of BIQM and similar models is the assumption of full employment, since the existence of hysteresis effects in labor markets is now acknowledged. To address hysteresis, we need models that are not only demand-led in the short run. There is a long tradition of post-Keynesian models that do not assume full employment and claim that the Keynesian Hypothesis (investment determines saving in both the short and long-run) holds also in the long run. ${ }^{2}$ Second, a large portion of the literature has long argued against the use of aggregate production functions. ${ }^{3}$ Following from the earlier discussion, it becomes clearer that the economy's potential rate of growth is endogenous to the system. Furthermore, it is quite striking how, especially in central banks, the centrality of money and its endogeneity are explicitly discussed in numerous policy briefs and monetary policy bulletins ${ }^{4}$ but, when it comes to modeling choices, monetarism reenters from the backdoor. Finally, it is worth noting that also the so-called "monetary policy rules" contain some serious omissions, most notably the absence of the exchange rate. ${ }^{5}$

The modeling of consumption still relies on the representative-agent permanent income hypothesis, which usually ignores shifts in credit constraints. For all models reviewed, all components of financial and housing wealth are lumped up in a single net worth or net wealth measure that enters the consumption function. This may however be problematic, as discussed many times by Muellbauer (2016). Given that housing is a consumption good like any other asset, the difference is that consumption will respond to changes in housing wealth differently than to an increase in financial wealth. Moreover, the different assets in the sector's balance sheet have different degrees of liquidity, i.e., stock market wealth is of course less accessible than cash, implying there should be different propensities to consume related to different assets classes, distinguishing between liquid and illiquid financial assets. Most importantly, the stock of net financial wealth of each institutional sector is

\footnotetext{
${ }^{2}$ It is worth stressing that post-Keynesians refuse even the existence of a NAIRU, and much has been written against the empirical underpinnings of the neoclassical Phillips curve; see Stockhammer (2008) for a critique of the NAIRU and Stockhammer et al. (2014) for a post-Keynesian alternative.

${ }^{3}$ See Lavoie (2014) and Shaikh (2016) for a discussion.

${ }^{4}$ See McLeay, Amar, and Thomas (2014).

${ }^{5}$ Examples of such rules may be found at:

https://www.federalreserve.gov/monetarypolicy/policy-rules-and-how-policymakers-use-them.htm
} 
disconnected from the net lending of the same sector, which in turn is determined by saving and investment decisions. ${ }^{6}$ Finally, the effect of debt on spending shall be carefully addressed, since it carries debt servicing and the associated default risks, which typically imply adverse consequences.

To close, we should underline again some important deficiencies. First, a detailed account of the financial sector and of the assets and liabilities in the sectors' balance sheets is missing. Second, households are assumed to hold all financial assets in the system (which are assumed not to be relevant in the short run) and debit-credit streams are not precisely modeled. Finally, the feedback effects of stocks on flows are not precisely addressed, as well as the overall effects on portfolio behavior. In such settings, thus, financial stability implications are difficult, if not impossible, to detect and analyze.

In the next two sections we will show how to deal with all the problems highlighted above within the SFC framework built in the spirit of Godley.

\section{Model Structure}

The first advantage of the SFC approach is its ability to capture the interrelations in expenditure-saving decisions and their implications for financial markets. Consistency requires the identification of whoto-whom relationships between institutional sectors for payments/receipts, and for creditor/debtor relations, which may not be directly available from the data published in the nonfinancial and financial accounts of institutional sectors, but can sometimes be inferred from other statistics, such as the balance of payments or government accounts.

From this point of view, exploiting the information available in the accounts of the institutional sectors already implies an advantage over models based only on national account statistics that lack sectoral details. The accounts of institutional sectors became available in 1955 in United States and in Italy in $1964^{7}$ but are rarely, if at all, employed by macroeconomic modelers.

The choice of the model's level of detail model can rely on the information available for such statistics, coupled with the research question we want to address with the model. In our case, the model is meant

\footnotetext{
${ }^{6}$ While the stock of real wealth, in contrast, is usually correctly modeled as the result of investment decisions, and possibly net capital gains on housing.

${ }^{7}$ Even though a first "national monetary balance sheet," produced by the BoI's research department led by Paolo Baffi, appeared in the 1948 Annual Governor's Report; see De Bonis and Gigliobianco (2012) for further details.
} 
to be used as a tool for evaluating policy scenarios. It therefore needs to have an adequate degree of detail for evaluating specific policy options, and be based on data at quarterly frequency, since annual data are released with too much delay to be useful for policy purposes.

Combining the information available from sectoral statistics, and following the procedure discussed in Zezza and Zezza (2019), we chose to disaggregate the balance sheet of all sectors as reported in table $1 .^{8}$

The stock of productive capital has been split into nonresidential building (KNR) and other productive capital (KM), which will be used in the model as determinants of investment functions based on a target capital-output ratio. Public capital (KG), linked to public investment, can be used to test the impact government expenditure on capital account has on private sector productivity.

${ }^{8}$ Data sources and the procedures used to estimate some model variables are reported in appendix I. 


\begin{tabular}{|c|c|c|c|c|c|c|c|}
\hline \multirow[t]{2}{*}{ Assets/liabilities } & \multicolumn{7}{|l|}{ Sector } \\
\hline & $\mathrm{HH}$ & $\mathrm{NFC}$ & $\mathrm{FC}$ & $\mathrm{CB}$ & GVT & RoW & Total \\
\hline \multicolumn{8}{|l|}{ Real assets } \\
\hline Capital (residential) & $+\mathrm{KH}$ & & & & & & $+\mathrm{KH}$ \\
\hline $\begin{array}{l}\text { Capital (nonresidential): } \\
\text { Machineries }\end{array}$ & & $+\mathrm{KM}$ & & & & & $+\mathrm{KM}$ \\
\hline $\begin{array}{l}\text { Capital (nonresidential): } \\
\text { Warehouses }\end{array}$ & & $+\mathrm{KNR}$ & & & & & $+\mathrm{KNR}$ \\
\hline Capital (public) & & & & & $+\mathrm{Kg}$ & & $+\mathrm{Kg}$ \\
\hline \multicolumn{8}{|l|}{ Financial assets } \\
\hline Gold & & & & + GOLD & & -GOLD & 0 \\
\hline Monetary base & $+\mathrm{MB} \_\mathrm{hh}$ & & $+\mathrm{MB} \_\mathrm{fc}$ & $-\mathrm{MB}$ & & $+\mathrm{MB} \_\mathrm{t} 2$ & 0 \\
\hline $\mathrm{CB}$ refinancing & & & $-\mathrm{ADV}$ & $+\mathrm{ADV}$ & & & 0 \\
\hline Bank deposits & +DEPS_hh & +DEPS_nfc & -DEPS & & +DEPS_gvt & +DEPS_row & 0 \\
\hline Bank loans: cons. credit & -BLcc & & + BLcc & & & & 0 \\
\hline Bank loans: mortgages & -Blmo & & $+\mathrm{B} \operatorname{lmo}$ & & & & 0 \\
\hline Bank loans to firms & & -BLfirms & +BLfirms & & & & 0 \\
\hline Banks debt & $+\mathrm{BB} \_\mathrm{hh}$ & & $-\mathrm{BB}$ & & & + BB_row & 0 \\
\hline Banks equities & $+\mathrm{EB}$ & & $-\mathrm{EB}$ & & & & 0 \\
\hline Public debt & + B_hh & $+\mathrm{B} \_\mathrm{nfc}$ & $+\mathrm{B} \_\mathrm{fc}$ & $+\mathrm{B} \_\mathrm{cb}$ & $-B$ & + B_row & 0 \\
\hline Firms equities & $+\mathrm{EN} \_\mathrm{hh}$ & $-\mathrm{EN}$ & $+\mathrm{EN} \_\mathrm{fc}$ & & $+\mathrm{EN} \_g v t$ & & 0 \\
\hline Outgoing FDI & & +FDIo & & & & -FDIo & 0 \\
\hline Incoming FDI & & -FDIi & & & & +FDIi & 0 \\
\hline Foreign liabilities & $+F_{-}$hh & & $+\mathrm{F}_{-} \mathrm{fc}$ & $+F \_c b$ & & $-F$ & 0 \\
\hline Other net & + ONFA_hh & + ONFA_nfc & $+\mathrm{ONFA} \_\mathrm{fc}$ & $+\mathrm{ONFA}$ cb & + ONFA_gvt & + ONFA_row & \\
\hline Net financial assets & NFA_hh & NFA_nfc & NFA_fc & NFA_cb & NFA_gvt & NFA_row & 0 \\
\hline
\end{tabular}


Figure 1. Italy: Household Wealth

Figure 1. Italy. Household wealth
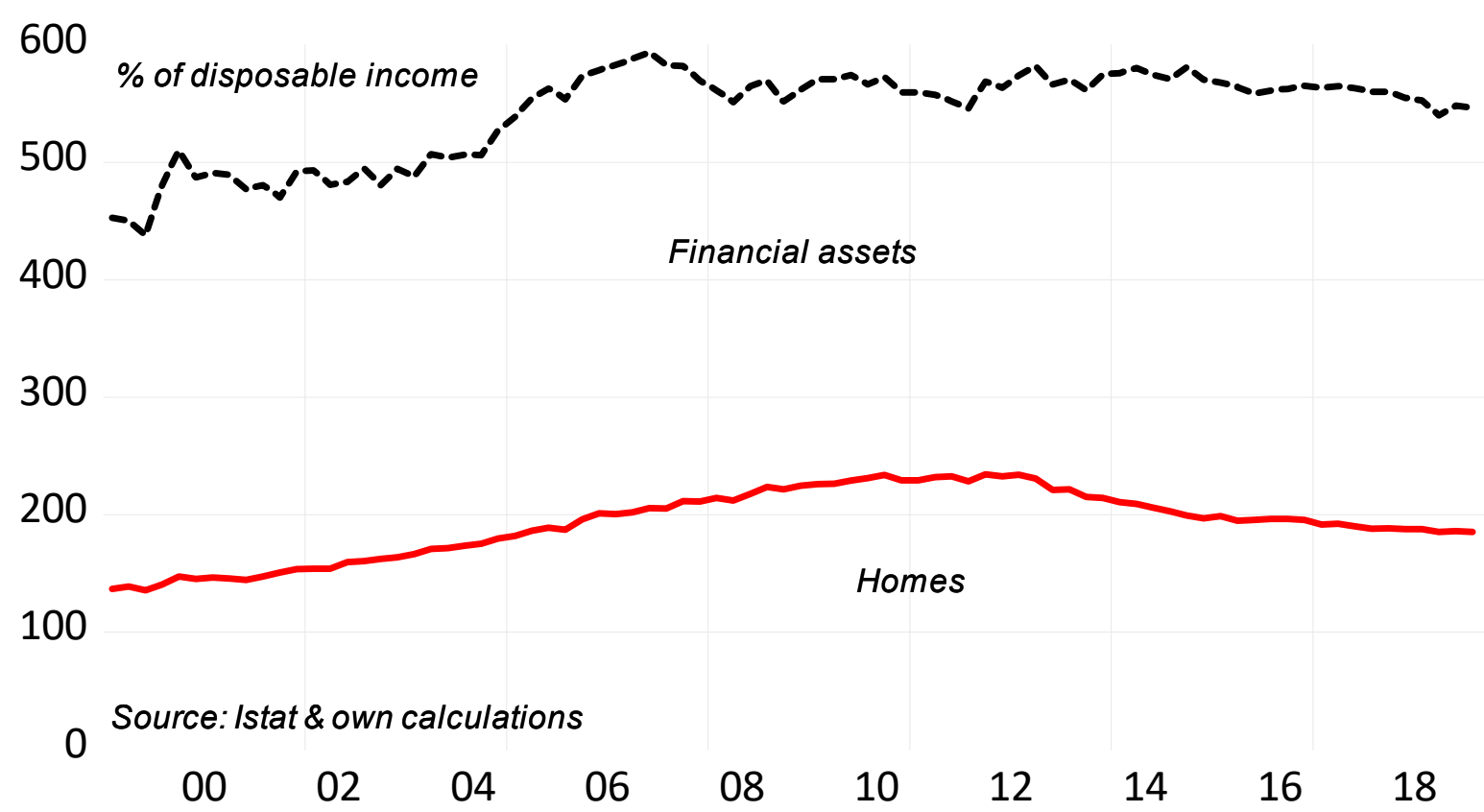

Source: ISTAT and own calculations

The relevance of stock measures for the determination of income and expenditure trajectories can be appreciated from the data in figure 1, where we report the evolution of the stocks of housing and gross financial assets for the household sector over time, both measured relative to household disposable income.

It is well-known that in Italy investment in housing has always been considered a safer alternative to the purchase of financial assets in a household's portfolio, so that a portion of the value of existing homes should be considered as a source of future revenue for the retirement years. This is part of the reason why Italian institutions are less financially sophisticated than similar economies. ${ }^{9}$

As the chart in figure 1 shows, the value of household housing wealth increased rapidly before the Great Recession, both because of real investment and because of the relative increase in the price of housing. It stabilized around 2009 and has decreased steadily, due to both the collapse in investment

\footnotetext{
${ }^{9}$ See Gola et al. (2017).
} 
and the fall in the market price of homes. Household financial wealth has been less volatile. It still much higher than the stock of household liabilities (not shown in the chart), which has more than doubled between 1996 and 2009, rising to 55 percent of GDP, and has been slowly falling in the last years. One of the purposes of an SFC model like ours is to evaluate the impact of such changes in the market value of wealth on household expenditure and saving decisions.

For financial assets and liabilities, we integrated the information available in the Financial Accounts of Institutional Sectors (FAIS) with other monetary statistics published by the BoI ${ }^{10}$ to achieve: (a) an adequate representation of the monetary aggregates relevant for monetary policy; (b) debtor-creditor relationship for each asset (while in the FAIS each sector often has the same asset on both sides of its balance sheet); and (c) an explicit representation of the major types of credit from both domestic and foreign financial institutions to the nonfinancial domestic sectors. For other financial instruments that we deemed less interesting for our purposes, we chose to use a residual category, other net financial assets (ONFA), trying to keep it to a relatively small size.

\section{Figure 2. Italy: Government Debt}

Figure 2. Italy. Government debt

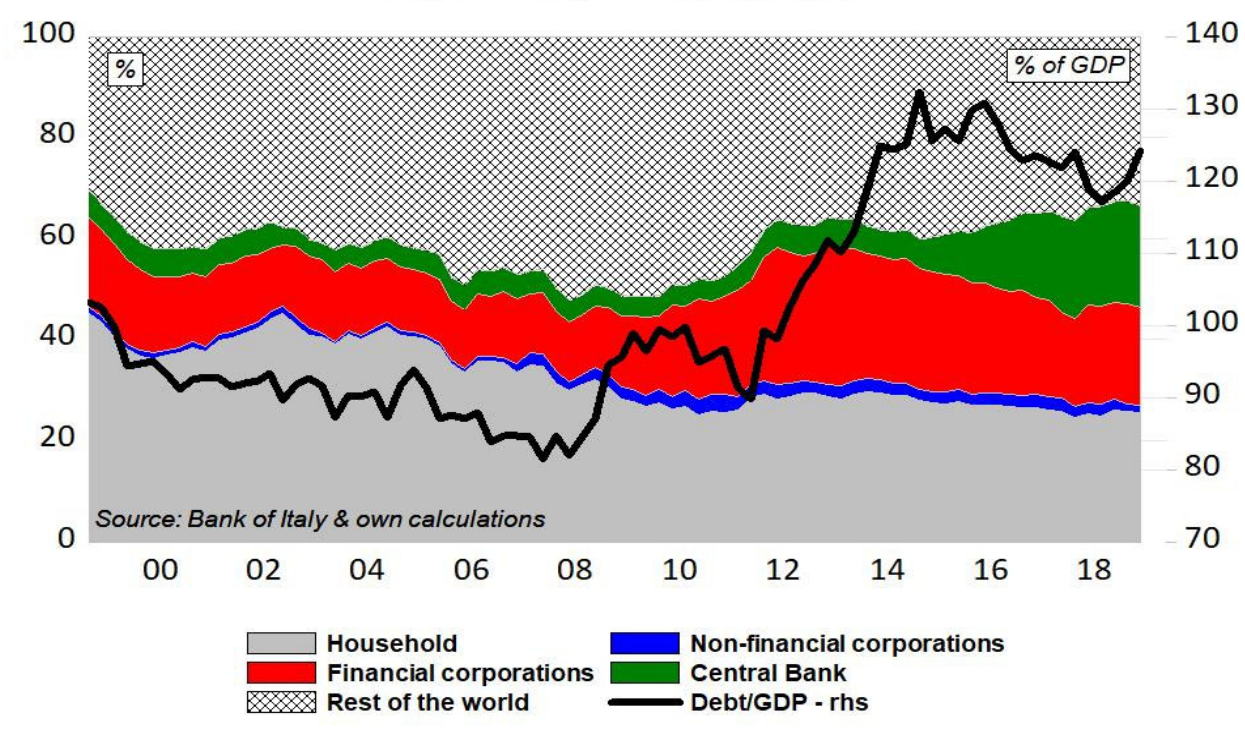

Source: BoI and own calculations

${ }^{10}$ See appendix I for details. 
Figure 3. Italy: Household Portfolio

Figure 3. Italy. Household portfolio

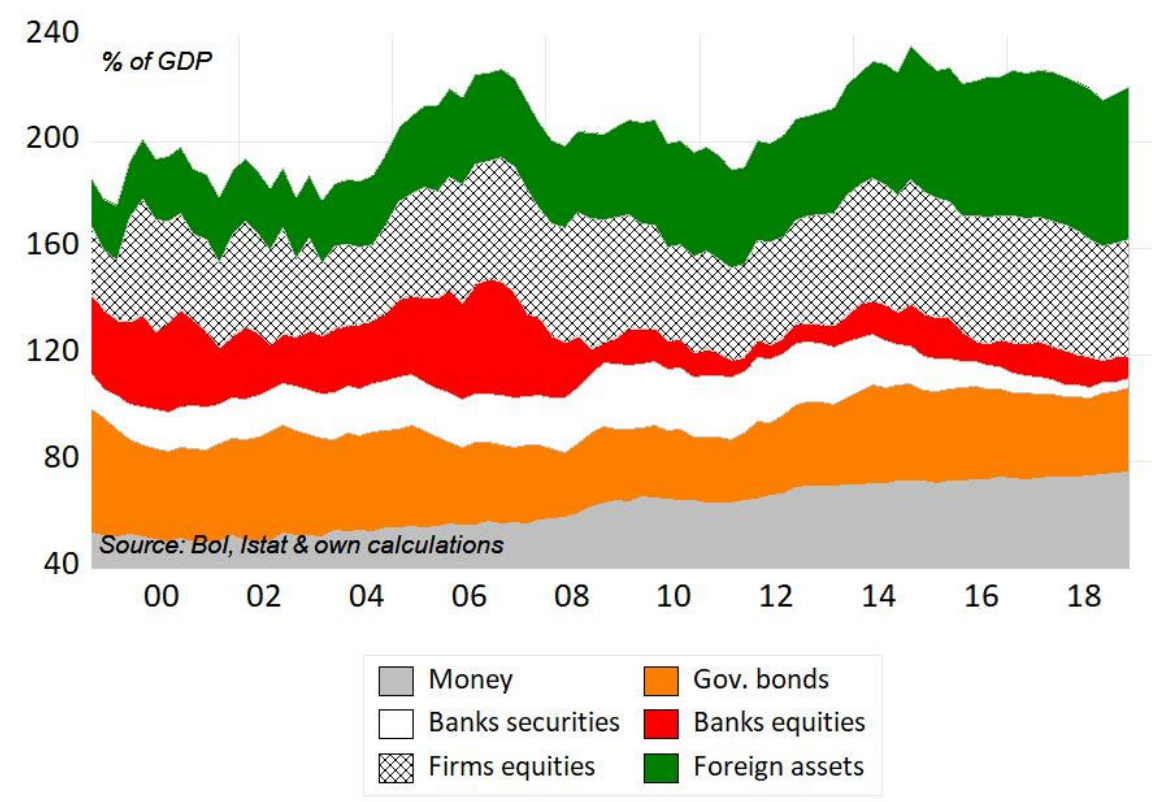

Source: BoI, ISTAT, and own calculations

What an SFC model for Italy should capture is the dynamics of Italian public debt to evaluate its sustainability under the current eurozone rules. The evolution of Italian public debt is reported in figure 2. It shows that the debt was slowly declining until the Great Recession, increased moderately relative to GDP with the crisis, and increased considerably with the crisis of confidence that started with the Greek crisis around 2011. The debt rose from 87 percent of GDP in the last quarter of 2011 to 129 percent of GDP in 2015, and declined again with the start of the second phase of the ECB's quantitative easing $(\mathrm{QE})$, when the BoI — on behalf of the ECB — started purchasing large amounts of bonds from the market.

The chart in figure 2 also shows that the share of public debt held directly by Italian households has been declining steadily, with households shifting a growing share of their portfolio toward assets issued by nonbank financial intermediaries, such as pension funds. The value of such assets in a household's portfolio has similar dynamics with the value of public bonds held by such intermediaries so that we chose to simplify the model's balance sheet; considering that households indirectly hold the public debt owned by these intermediaries, we removed their liabilities from the asset side of household's balance sheet. 
Other examples of the SFC approach's strengths over a simple model for flows are related to the determination of the composition of the household's portfolio and its relevance for financial markets and economic policy. In figure 3 we report the major financial assets in a household's portfolio (after the consolidation mentioned above). We could summarize the dynamics in figure 3 as a "search for safety" over the whole period: the share of very liquid assets (monetary base plus bank deposits) has been growing steadily from about 50 percent of GDP to over 70 percent of GDP, while the holding of riskier assets - such as banks' equities and bonds - has been declining. Household also steadily increased their holding of foreign assets. ${ }^{11}$

Once the balance sheet of the model has been designed, it is easier to determine a consistent set of income flows between sectors. In table 2 we report a simplified description of the main accounting relations between our institutional sectors, obtained by adding who-to-whom closures on the available data for nonfinancial transactions.

${ }^{11}$ Which is the sum of short- and long-term instruments plus the shares of mutual funds issued by the RoW. 
Table 2. Italy: Transaction Matrix

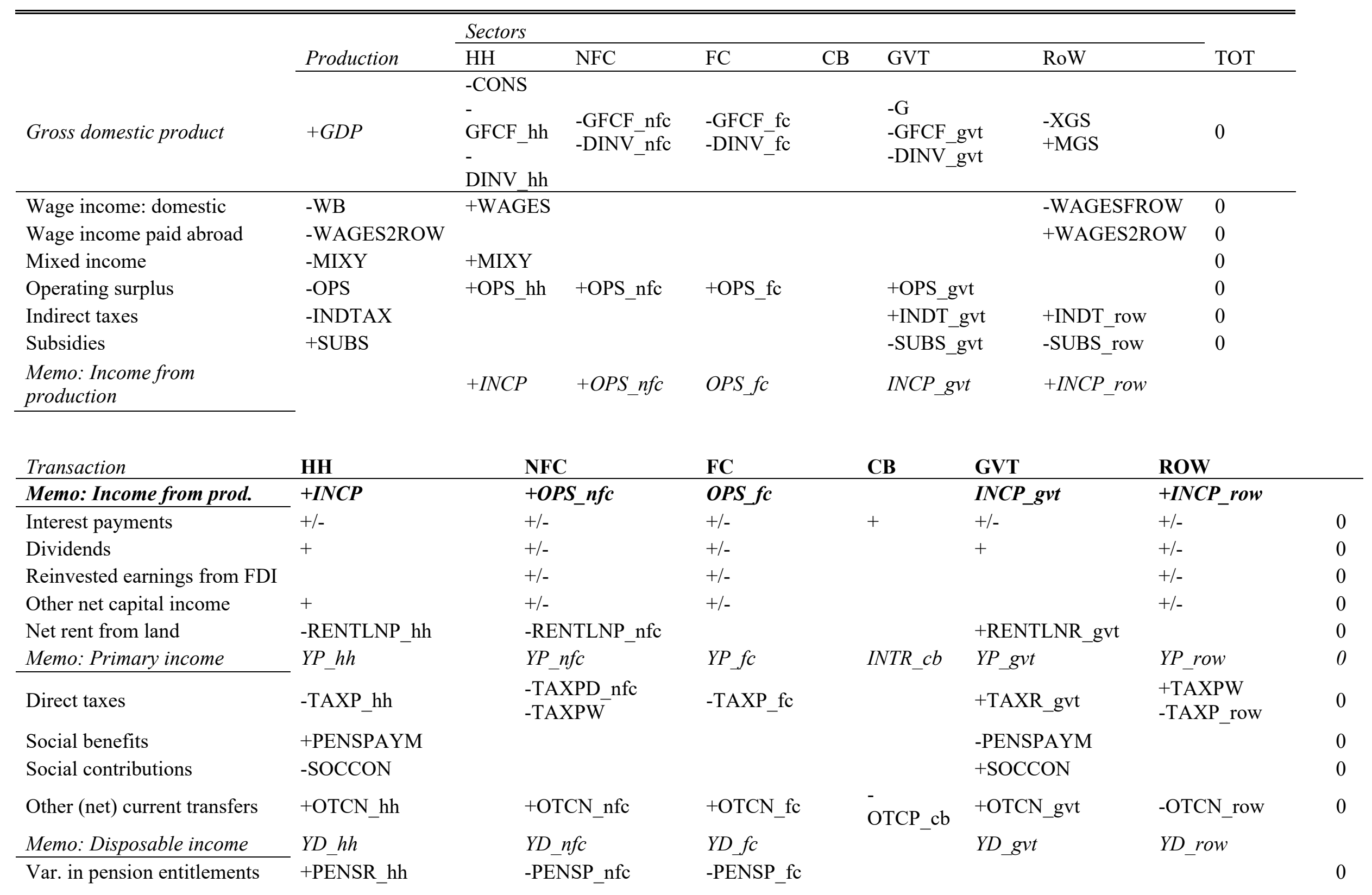




\begin{tabular}{|c|c|c|c|c|c|c|c|}
\hline Memo: final demand & $-C O N S$ & & & & $-G$ & $-X G S+M G S$ & \\
\hline Memo: Savings & $+S A V \_h h$ & $+S A V \_n f_{c}$ & $+S A V \_c$ & 0 & $+S A V \_g v t$ & $+S A V \_r o w$ & 0 \\
\hline Taxes on capital account & -TRKTAX_P_hh & $\begin{array}{l}- \\
\text { TRKTAX_PD_nfc } \\
- \\
\text { TRKTAX_PW_nf } \\
\text { c }\end{array}$ & -TRKTAX_P_fc & & +TRKTAX_R_gvt & $\begin{array}{l}+ \text { TRKTAX_PW } \\
\text { nfc }\end{array}$ & 0 \\
\hline Transfer on capital account & -NTRK_hh & -NTRK_nfc & -NTRK_fc & & +NTRK_gvt & & 0 \\
\hline $\begin{array}{l}\text { Other nonproduced, } \\
\text { nonfinancial assets }\end{array}$ & -OTHDNA_hh & -OTHDNA_nfc & -OTHDNA_fc & & -OTHDNA_gvt & & 0 \\
\hline Memo: final demand & $\begin{array}{l}-G F C F_{-} h h \\
-D I N V_{-} h h\end{array}$ & $\begin{array}{l}-G F C F_{-} n f c \\
-D I N V_{-} n f c\end{array}$ & $\begin{array}{l}-G F C F \_f c \\
-D I N V_{\_} f c\end{array}$ & & $\begin{array}{l}-G F C F \_g v t \\
-D I N V \_g v t\end{array}$ & & \\
\hline Net lending & NETLEND_hh & NETLEND_nfc & $N E T L E N D \_f c$ & 0 & NETLEND_gvt & NETLEND_row & 0 \\
\hline
\end{tabular}




\section{The Model}

In this subsection we will describe, sector by sector, all of the model's accounting identities and behavioral equations. ${ }^{12}$ We start from the production block of table 2.

\section{Gross Domestic Product}

GDP at constant prices (GDPK, eq.1) is given by the sum of the components of demand, namely consumption (CONSK), investments and changes in inventories (GFCFK and DINVK, respectively), government expenditures $(G K)$, and exports $(X G S K)$ minus imports $(M G S K)$, as in the first row of table 2.

$$
\begin{aligned}
& G D P K=C O N S K+G F C F K+D I N V K+G K+X G S K-M G S K+G D P K_{D I S C} \\
& G D P=C O N S+G F C F+D I N V+G+X G S-M G S
\end{aligned}
$$

For variables measured at constant prices we use the published figures at chained 2010 prices, which have the property that the sum of the components of real GDP does not sum up to the total, so that a residual (GDPKRES) must be introduced to keep consistency between variables at current and constant prices. We need a similar residual variable when we consider detailed components of demand, as is the case for investment and exports.

The components of GDP will be determined at constant prices and converted to current prices using their own deflators (rather than assuming a unique deflator):

$$
\begin{aligned}
& \text { CONS }=\text { CONSK } \cdot p^{C O N S} \\
& G F C F=G F C F_{H}+G F C F_{P}+G F C F_{M}+G F C F_{G} \\
& G F C F K=G F C F K_{H}+G F C F K_{P}+G F C F K_{M}+G F C F K_{G}+G F C F K_{D I S C} \\
& G F C F_{H}=G F C F K_{H} \cdot p^{G F C F H} \\
& G F C F_{P}=G F C F K_{P} \cdot p^{G F C F N R} \\
& G F C F_{M}=G F C F K_{M} \cdot p^{G F C F M} \\
& G F C F_{G}=G F C F K_{G} \cdot p^{G F C F N R} \\
& G=G K \cdot p^{G}
\end{aligned}
$$

\footnotetext{
${ }^{12}$ We will use a K after the variable name (i.e., GDPK) to denote constant prices variables, otherwise variables are in nominal amounts. A full description of the equations defining prices and deflators is given in appendix II.
} 


$$
\begin{aligned}
& X G S=X G+X S \\
& X G S K=X G K+X S K+X G S_{D I S C} \\
& X G=X G K \cdot p^{X G} \\
& X S=X S K \cdot p^{X S} \\
& M G S=M G S K \cdot p^{M G S} \\
& p^{G D P}=G D P / G D P K
\end{aligned}
$$

Consistent with the measures of real wealth in table 1, investment is split into housing $\left(G F C F K_{H}\right)$, nonresidential $\left(G F C F K_{P}\right)$, and machinery $\left(G F C F K_{M}\right)$, which also includes other, smaller categories. Public investment $\left(G F C F K_{G}\right)$ is mainly nonresidential, so we use the same deflator ( $\left.p^{G F C F N R}\right)$ adopted for private nonresidential investment.

Exports are split into goods and services. We checked whether model performance would improve by splitting imports along similar lines and decided against it.

From the income side (the first column of table 2), GDP is equal to the sum of wages paid domestically and to foreigners ( $W B$ and $W A G E S 2 R O W$, respectively), mixed income (MIXY), gross operating surplus (OPS), and indirect taxes and subsidies to production (INDTAX and SUBS, respectively).

The level of employment (EMP) is determined by real GDP and average labor productivity (PROD). Given the average unit wage, the wage bill is obtained. Wages accruing to domestic households are given by this wage bill (WB), less wages paid to foreigners (WAGES2ROW), plus wages earned abroad by residents (WAGESFROW). These income payments to/from the foreign sectors are not modeled yet, but the model could easily be extended to account for the role of immigrant workers, and possibly increase the level of detail of wages paid in the labor market.

Mixed income is simply obtained as a share of GDP. Indirect taxes (INDTAX) and subsidies (SUBS) are modeled with an implicit ex post rate to GDP.

Profits — or the gross operating surplus — is the residual category. 


$$
\begin{aligned}
& E M P=G D P K / P R O D \\
& W B=\text { wageu } \cdot E M P \\
& W A G E S=W B+\text { WAGESFROW }- \text { WAGES } 2 R O W \\
& M I X Y=\text { ratio }^{\text {mixy }} \cdot G D P \\
& \text { INDTAX }=\theta^{i} \cdot G D P \\
& S U B S=\theta^{S} \cdot G D P \\
& O P S=G D P-(W B+\text { MIXY +INDTAX -SUBS })
\end{aligned}
$$

Gross operating surplus is allocated to the different institutional sectors according to exogenous shares (eq. 23 through eq. 26), with nonfinancial corporations' profits $\left(O P S_{n f c}\right)$ determined residually.

$$
\begin{aligned}
& O P S_{h h}=\pi_{h h} \cdot O P S \\
& O P S_{f c}=\pi_{f c} \cdot O P S \\
& O P S_{g v t}=\pi_{g v t} \cdot O P S \\
& O P S_{n f c}=O P S-\left(O P S_{h h}+O P S_{f c}+O P S_{g v t}\right)
\end{aligned}
$$

Indirect taxes and subsidies are allocated between European Union (EU) institutions and the government by calculating the amounts accruing to foreigners as the product of the corresponding implicit tax rates times the total payments (in equations eqs. 28 and 30) and computing the government receipts residually (in equations 29 and 31 ).

$$
\begin{aligned}
& I N D T_{\text {row }}=\theta^{i w} \cdot I N D T A X \\
& I N D T_{\text {gvt }}=I N D T A X-I N D T_{\text {row }} \\
& S U B S_{\text {row }}=\theta^{s w} \cdot S U B S \\
& S U B S_{\text {gvt }}=S U B S-S U B S_{\text {row }}
\end{aligned}
$$




\section{Households}

Households collect their income from production $\left(I N C P_{h h}\right)$, which is the sum of domestic salaries $(W A G E S)$, mixed income $(M I X Y)$, and operating surplus $\left(O P S_{h h}\right)$. Following the description made above, WAGES, MIXY, and $O P S_{h h}$ are determined in the production account, and the amount of profits accruing to households is given by an exogenous share:

$$
I N C P_{h h}=W A G E S+M I X Y+O P S_{h h}
$$

Household primary income is given by income from production, plus income from capital obtained from other sectors, less payments made to other sectors. Households receive capital income (eq. 33), which is the sum of interest received on their holdings of bank deposits, public debt, banks debt instruments and foreign assets $\left(I N T R_{h h}\right)$, dividends on their stocks of firms' and banks' shares $\left(D I V R_{h h}\right)$, and other net capital income $\left(K Y N E T_{h h}\right)$. Households pay interest incomes on the stock of loans for both consumer credit and mortgages $\left(I N T P_{h h}\right)$ and rent from land ownership to the government $\left(R E N T L N_{h h}\right)$.

$$
\begin{aligned}
& Y P_{h h}=I N C P_{h h}+\left(I N T R_{h h}+D I V R_{h h}+K Y N E T_{h h}\right)-\left(I N T P_{h h}+\operatorname{RENTLN}_{h h}\right) \\
& I N T R_{h h}=\left(r_{t}^{\text {deps }} \cdot D E P S_{H H, t-1}+r_{t}^{b} \cdot B_{H H, t-1}+r_{t}^{b b} \cdot B B_{h h, t-1}+r_{t}^{f} \cdot F_{h h, t-1}\right)- \\
& \text { DISC_INTR } R_{h h} \\
& D I V R_{h h}=\left(r_{t}^{e n} \cdot E N_{h h, t-1}+r_{t}^{e b} \cdot E B_{h h, t-1}\right)+D I S C_{-} D I V R_{h h} \\
& K Y N E T_{h h}=K I N C O \_R_{h h} \\
& I N T P_{h h}=\left(r_{t}^{b l c c} \cdot B L C C_{t-1}+r_{t}^{b l m o} \cdot B L M O_{t-1}\right)-D I S C_{-} I N T P_{h h} \\
& R E N T L N_{h h}=R E N T L N_{g v t}-R E N T L N_{n f c}
\end{aligned}
$$

Notice that we needed some residual variables in equations 34,35 , and 37 to keep consistency. This is because we computed a single interest rate — or rate of return — for each financial asset and obtained the flow of income by multiplying the appropriate interest rate with our measure of the opening stock. This implied a difference from the measure of income from capital published in the accounts of the household sector. The same will apply to the other institutional sectors discussed below. 
Disposable income of the household sector $\left(Y D_{h h}\right)$ is obtained by adding pension payments and other net transfers to primary income and subtracting social contributions and tax payments. We determine total pension receipts by households as the sum of the payments made by the other sectors, which are determined through exogenous shares in total payment. Taxes are generated by the model from an average ex post implicit tax rate on the sum of household primary income and pensions received. Social contributions - paid to all other domestic sectors - are computed applying an implicit ex post rate on household income from production.

$$
\begin{aligned}
& Y D_{h h}=Y P_{h h}+\left(P E N S P A Y M+O T C N_{h h}\right)-\left(T A X P_{h h}+S O C C O N\right) \\
& P E N S P A Y M=P E N S P A Y M_{g v t}+P E N S P A Y M_{n f c}+P E N S P A Y M_{f c}+P E N S P A Y M_{\text {row }}(40 \\
& O_{\text {OTCN }}=\text { OTCN_TOThh } \\
& T A X P_{h h}=\theta_{h h}^{d} \cdot\left(Y P_{h h}+\text { PENSPAYM }\right) \\
& \text { SOCCON }=\theta^{\text {SC }} \cdot\left(\text { WAGES }+ \text { MIXY }+O P S_{h h}\right)
\end{aligned}
$$

Households saving $\left(S A V_{h h}\right)$, in turn, is the result of what is left of disposable income after consumption and the revaluations in pension entitlements. The variations in pension entitlements are completely determined by the payments of the other productive sectors (eq. 45), while households' final consumption (as obtained from the sectoral accounts) is given by consumption from the National Income and Product Accounts (NIPA) and a discrepancy ${ }^{13}$ (eq. 46).

$$
\begin{aligned}
& S A V_{h h}=Y D_{h h}+P E N S R_{h h}-C O N S F \\
& P E N S R_{h h}=P E N S R_{n f c}+P E N S R_{f c} \\
& \text { CONSF }=\text { CONS }+ \text { DISC_CONS }
\end{aligned}
$$

Following Godley and Lavoie (2007) and the common practice in the SFC literature, we select the determinants of consumption to be coherent with a dynamic process of adjustment toward a stable stock-flow norm between household income and wealth. For the econometric specification, we adopt a pragmatic approach, taking care of the order of integration of each variable in the models. In the case of consumption, we use an error correction approach, estimating separately the long-run coefficients

${ }^{13}$ The discrepancy arises from the fact that we needed to seasonally adjust the data from the institutional accounts, while NIPA data were already seasonally adjusted. 
linking real consumption per capita to real disposable income and wealth per capita, and a dynamic specification where we find that share prices also play a role.

\begin{tabular}{|c|c|c|}
\hline \multirow[t]{2}{*}{ Consumption } & & \multirow{6}{*}{$\begin{array}{l}\text { Method: FMOLS } \\
\text { Sample: } 1999 \mathrm{q} 3-2019 \mathrm{q} 2 \\
\text { Adj-R2: } 0.939 \\
\text { E-G tau: }-5.367^{* * *}\end{array}$} \\
\hline & Long-run coefficients & \\
\hline Real disposable income & $0.681 * * *$ & \\
\hline Real wealth & 0.001 & \\
\hline \multirow[t]{3}{*}{ Interest rate (consumer credit) } & & \\
\hline & $-0.061^{* * *}$ & \\
\hline & Short-run coefficients & \\
\hline Real disposable income & $0.281 *$ & Method: OLS \\
\hline Share price & $0.097 * *$ & Sample: $1999 q 2-2019 q 2$ \\
\hline Interest rate (consumer credit) & $-0.043 * *$ & Adj-R2: 0.587 \\
\hline Error correction term & $-0.249 * * *$ & D.W.: 2.081 \\
\hline
\end{tabular}

Notes: E-G tau is the Engle-Granger tau statistic for the cointegration test

Using the fully modified OLS (FMOLS) approach, we find cointegration among real consumption per capita, real disposable income per capita, and the opening stock of real wealth, as well as the interest rate on consumer credit after 2008. We find a structural break in the propensity to consume out of disposable income in the first quarter of 2009, with an increase in such propensity after that date. In the table we report only the final values of the coefficients. ${ }^{14}$ Using symbols, the error correction term (CONSK_CE) is given by:

$$
C O N S K_{-} C E=\frac{C O N S K}{P O P}-f\left(\frac{Y D_{h h}}{P O P \cdot p^{c o n s}} ; \frac{N F A_{-} H P_{h h}}{P O P \cdot p^{c O n s}}+\frac{\mathrm{KHK}}{P O P} ; r^{b l c c}\right)
$$

In the short run, the changes in real consumption per capita depend positively on disposable income $\left(Y D_{h h}\right)$ and changes in domestic share prices $\left(s p^{i t}\right)$, and negatively on the interest rate on short-term loans to households $\left(r^{b l c c}\right)$.

$$
\begin{aligned}
& \Delta \frac{\text { CONSK }}{P O P}=-\rho \cdot \text { CONSK_CE }_{t-1}+\sum_{i=1}^{k} \beta_{i} \cdot \Delta \frac{\text { CONSK }_{t-i}}{P O P_{t-i}}+\sum_{i=0}^{k} \gamma_{i} \cdot \Delta{\frac{Y D_{h h, t-i}}{P O P_{t-i} \cdot p_{t--i}^{C O N S}}}^{C O N} \\
& \sum_{i=1}^{k} \delta_{i} \cdot \Delta S P_{-} I T_{t-i}+\sum_{i=1}^{k} \varphi_{i} \cdot \Delta r_{t-i}^{b l c c}
\end{aligned}
$$

\footnotetext{
${ }^{14}$ Real wealth per capita is not significant in the current specification, but we kept this variable, which has the right sign but a small magnitude, to respect the principle of convergence to a stable norm between wealth and income.
} 
For the short-run specifications we adopted the general-to-specific approach: starting from a general model in term of dynamics, we tested the restrictions on nonsignificant parameters to find the final parsimonious model.

Finally, the net lending position (NETLEND $D_{h h}$ in eq. 49) of the household sector is obtained by adding (subtracting) the transactions related to taxes and transfers on capital accounts (TRK_TAX and $T R K_{-} O$ ), and subtracting investments in real assets, which are split between gross fixed capital formation $\left(G F C F_{h h}\right)$, changes in inventories $\left(D I N V_{h h}\right)$, and the acquisitions of nonproduced, nonfinancial assets $\left(O T H D N A_{h h}\right)$. Household investment in dwellings and in inventories depends on exogenous shares in total housing investments (eq. 50) and total changes in inventories (eq. 51), respectively. In the long run, real investment in new houses (eq. 52) reacts negatively to the existing stock of buildings (in real terms) and positively to the changes in disposable income in terms of the price of investments in new houses, which is consistent with a process of adjustment to a stable stockflow ratio of housing wealth to income. The interest rate on mortgages also has a negative impact in the long term. We added three dummies to model structural breaks, as suggested by Eviews when running the appropriate tests. We estimate the NIPA measure of the changes in inventories in real terms as a stock-flow adjustment toward a stable inventories-to-GDP ratio (eq. 53). We also link the sectoral account measure of real changes in inventories with the NIPA definition ${ }^{15}$ to achieve accounting consistency (eqs. 54 and 55). The stock of inventories at current prices is computed by multiplying the variable at constant prices by the GDP deflator (eq. 56). Finally, we differentiate our stock variable to obtain the relative flow (eq. 57).

$$
\begin{aligned}
& N E T L E N D_{h h}=S A V_{h h}+\left(T R K_{-} O R_{h h}-T R K_{-} T A X P_{h h}-T R K_{-} O P_{h h}\right)-G F C F_{h h}-D I N V_{h h}- \\
& \text { OTHDNA } A_{h h} \\
& G F C F_{h h}=\operatorname{ratio}_{h h}^{G F C F}+G F C F_{H} \\
& D I N V_{h h}=\text { ratio dinv }_{h h}^{\text {dinv }} \text { DINV } \\
& \Delta G F C F K_{h}=f\left(\frac{Y D_{h h, t-1}}{p_{t-1}^{g f c f}} ; K H K ; r^{b l m o}\right)
\end{aligned}
$$

\footnotetext{
${ }^{15}$ Inventories in national accounts are obtained residually and are not a good indicator for inventories in theoretical models. Therefore, we used a simple approach that ensures convergence to a stable stock-flow ratio of inventories to GDP. In future developments of the model, we will try to verify if inventories can be treated as a buffer when expectations on demand are introduced.
} 


$$
\begin{aligned}
& \frac{D I N V K}{G D P K}=f\left(A R 1 ; \frac{I N V K_{t-1}}{G D P K_{t-1}}\right) \\
& \frac{D I N V K 2}{G D P K}=f\left(\frac{D I N V K}{G D P K}\right) \\
& I N V K=I N V K_{t-1}+D I N V K 2 \\
& I N V=I N V K \cdot p^{G D P} \\
& D I N V=d(I N V)
\end{aligned}
$$

\begin{tabular}{|c|c|c|}
\hline Households' investment & \multirow[b]{2}{*}{ Long-run coefficients } & \\
\hline eq. $\triangle G F C F K_{h}=f$ & & \\
\hline$\frac{Y D_{h h, t-1}}{p_{t-1}^{g f f}} ; K H K ; r b l m o($ & & \\
\hline $\begin{array}{l}\text { Disposable income in terms of } \\
\text { price of investment in new houses }\end{array}$ & $2.989 * * *$ & $\begin{array}{l}\text { Method: OLS } \\
\text { Sample: } 1999 q 2-2019 q 2\end{array}$ \\
\hline Real stock of housing & -3.771 & Adj-R2: 0.535 \\
\hline Interest rate (mortgages) & $-0.204 * *$ & \\
\hline
\end{tabular}

We now turn to households' portfolio behavior, i.e., how the changes in the net lending position translate into specular changes in the asset/liability structure of their balance sheet. As in all other sectors, net financial assets are determined (eq. 59) by cumulating net lending (NETLEND) and net capital gains (NKGAINS). ${ }^{16}$ We define households' illiquid assets as the sum of their stocks of banks' equities and shares, government bonds, NFC shares, and foreign assets (eq. 60). Finally, we have a residual category, "other net financial assets," which is determined as a portfolio adjustment (eq. 61).

$$
\begin{aligned}
& N E T L E N D F_{h h}=N E T L E N D_{h h}+D_{I S C} N E T L E N D_{h h} \\
& N F A_{h h}=N F A_{h h, t-1}+N E T L E N D F_{h h}+N K G A I N S_{h h} \\
& F A S S E T S_{h h}=B B_{h h}+E B_{h h}+E N_{h h}+F_{h h} \\
& O N F A_{h h}=N F A_{h h}+B L C C+B L M O-\left(D E P S_{h h}+M B_{h h}\right)-F A S S E T S_{h h}
\end{aligned}
$$

In the model, it is money - and thus liquidity — that links the past, the present, and the future, as in Keynes (1936). Thus, a household's first decision is about how much money they want to hold in liquid form (either banknotes or deposits at banks) in the future - which depends on economic activity, the unemployment rate, and a dummy for the sovereign debt crisis (eq. 62) — and how to split the cash

\footnotetext{
${ }^{16}$ See appendix 1 for the details on the measurement and determination of capital gains.
} 
between the two, which is done with a simple ratio determined by a trend and an autoregressive process (eq. 63).

$$
\begin{aligned}
& \frac{D E P S_{h h}+M B_{h h}}{Y D_{h h}}=f(\text { trend; AR1; UR }) \\
& \frac{\mathrm{MB}_{\mathrm{hh}}}{\mathrm{DEPS}_{\mathrm{hh}}}=\mathrm{f}(\text { trend; AR1) }
\end{aligned}
$$

\begin{tabular}{|c|c|c|}
\hline Demand for cash & & \\
\hline eq. $\frac{\mathrm{MB}_{\mathrm{hh}}}{\mathrm{DEPS}_{\mathrm{hh}}}=\mathrm{f}$ trend;AR1 & Coefficients & \\
\hline Trend & $0.001 * *$ & Method: ML \\
\hline AR1 & $0.852 * * *$ & $\begin{array}{l}\text { Sample: } 1999 q 1-2019 q 1 \\
\text { Adj-R2: } 0.965\end{array}$ \\
\hline
\end{tabular}

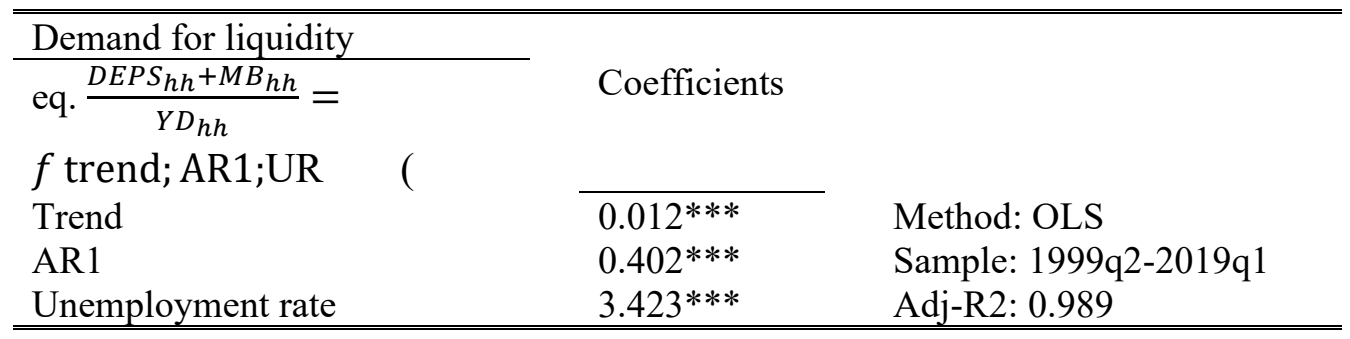

The next decision faced by households is how much debt they want to take on. In the model, households demand bank loans either to finance their housing investment through mortgages - the flow of which (relative to disposable income) is driven by household residential investment, the interest rate on mortgages, the existing stock of mortgage debt, and mortgages write-offs (eq. 64) — or for consumption purposes, which depends on consumption relative to income and the interest rate on consumer credit $^{17}$ (eq. 65).

$$
\begin{aligned}
& \frac{V B L M O}{Y D_{h}}=f\left(\frac{G F C F_{H, t-1}}{Y D_{h h, t-1}} ; r^{b l m o} ; \frac{B L M O_{t-1}}{Y D_{h h, t-1}} ; \frac{B L M O W O_{t-1}}{Y D_{h h, t-1}} ; S P R E A D\right) \\
& \frac{B L C C-B L C C_{t-4}}{Y D_{h}}=f\left(\frac{B L C C_{t-4}}{Y D_{h h, t-4}} ; A R 1 ; r^{b l c c} ; \frac{C O N S_{t-1}}{Y D_{h h, t-1}}\right)
\end{aligned}
$$

\footnotetext{
${ }^{17}$ We found a positive relation between consumer credit and the relevant interest rate, which may suggest a Ponzi scheme.
} 


\begin{tabular}{|c|c|c|}
\hline Demand for mortgages & & \\
\hline eq. 64 & Long-run coefficients & \\
\hline Investment in housing & $2.098 * * *$ & Method: OLS \\
\hline Interest rate (mortgages) & $-0.024 * * *$ & Sample: $2000 q 1-2019 q 1$ \\
\hline Existing stock of mortgages & $-0.076 * * *$ & Adj-R2: 0.869 \\
\hline Mortgages write-offs & $-2.376 * * *$ & \\
\hline Spread & $-0.014 * * *$ & \\
\hline Demand for consumer credit & & \\
\hline eq. 65 & Long-run coefficients & \\
\hline Existing stock of loans & $-0.201 * *$ & $\begin{array}{l}\text { Method: OLS } \\
\text { Sample: } 2000 q 1-2019 q 1\end{array}$ \\
\hline & Short-run coefficients & Adj-R2: 0.685 \\
\hline AR1 & & \\
\hline Interest rate (consumer credit) & $0.004 * *$ & \\
\hline Consumption & $0.320^{*}$ & \\
\hline
\end{tabular}

For the remaining demand for assets, our choice of methodology has been driven by what we may call a "pragmatic approach." This will be the focus of the next subsection.

\section{Households' Portfolios: Theory...}

One of the first proponents of the SFC approach was James Tobin (1969), whose portfolio theory of investment was later adopted by Godley —although from a post-Keynesian perspective - and integrated into SFC modeling (Godley and Lavoie 2007).

Suppose we have a closed system, with three financial assets (cash, bills, and bonds). A key assumption of SFC models is that households make a two-stage decision (Keynes 1936, 166). First, they decide how much to save out of income. Second, they decide how to allocate their wealth (including the newly acquired wealth). The decision happens in the same time period, but they still do follow a hierarchical order: "The consumption decision determines the size of the (expected) end-of-period stock of wealth; the portfolio decision determines the allocation of the (expected) stock of wealth" (Godley and Lavoie $2007,103)$ Thus, the difference between disposable income and consumption is equal to the change in total wealth.

How shall households allocate their wealth between the different assets? Brainard and Tobin (1968) and Tobin (1969) proposed a simple theory, which added the transaction demand for money to the Keynesian story of liquidity preference. 


$$
\begin{aligned}
& \frac{H_{d}}{V^{e}}=\lambda_{10}+\lambda_{12} \cdot r^{B}+\lambda_{13} \cdot E R r_{B L}+\lambda_{14} \cdot\left(Y D_{r}^{e} / V^{e}\right) \\
& \frac{B_{d}}{V^{e}}=\lambda_{20}+\lambda_{22} \cdot r^{B}+\lambda_{23} \cdot E R r_{B L}+\lambda_{24} \cdot\left(Y D_{r}^{e} / V^{e}\right) \\
& \frac{(p B L \cdot B L)}{V^{e}}=\lambda_{30}+\lambda_{32} \cdot r^{B}+\lambda_{33} \cdot E R r_{B L}+\lambda_{34} \cdot\left(Y D_{r}^{e} / V^{e}\right)
\end{aligned}
$$

Or, in matrix form:

$$
\left[\begin{array}{c}
H_{d} \\
B_{d} \\
B L_{d} \cdot p B L
\end{array}\right]=\left[\begin{array}{l}
\lambda_{10} \\
\lambda_{20} \\
\lambda_{30}
\end{array}\right] V^{e}+\left[\begin{array}{lll}
\lambda_{11} & \lambda_{12} & \lambda_{13} \\
\lambda_{21} & \lambda_{22} & \lambda_{23} \\
\lambda_{31} & \lambda_{32} & \lambda_{33}
\end{array}\right]\left[\begin{array}{c}
0 \\
r^{\mathrm{B}} \\
\mathrm{ERr}_{\mathrm{BL}}
\end{array}\right] V^{e}+\left[\begin{array}{c}
\lambda_{14} \\
\lambda_{24} \\
\lambda_{34}
\end{array}\right] Y D_{r}^{e}
$$

Households want to hold a certain share ( $\left.\lambda_{i 0}\right)$ of their wealth in the form of asset $i$, but this proportion is modified by the expected rate of return on this asset and by the level of expected (regular) disposable income. The 0 in the rate of return vector reflects the fact that cash does not bear interest. When making their portfolio allocations, households are concerned about the interest rate on bills $\left(r^{B}\right)$, which is determined at the end of the period and will generate the future interest payments, and by the expected return on bonds $\left(E R r_{B L}\right)$.

The coefficients in each equation follow from the assumption that people make consistent decisions on wealth allocation. Thus, the sum of the constants must be unity, as the decision to hold one asset implies the decision to hold the remaining wealth in the other two. In the same way, the sum of the coefficients with respect to each argument of the portfolio equations must be zero: if a change in interest (or income) makes people wish to hold a higher proportion of cash, it implies that they want to hold a lower proportion of bills and bonds (and vice versa). This is the adding-up constraint (Tobin 1969): if there are $m$ assets, one needs to specify $m-1$ as the demand function (the last one being implied by the rest), thus assuring that any increase in a stock implies a corresponding decrease in some other, and the same applies to the relative rate of returns (i.e., an increase in one rate implies that, at least, there is a specular change in another). 


\section{Households' Portfolios: ... and Practice}

When dealing with real world statistics, however, it is difficult to estimate from the data (given their structure, the available time span, the presence of structural breaks, etc.) the appropriate relations-if they exist - between the relative rate of returns and the demand and supply for different assets and liabilities. Nevertheless, the principles behind Tobin's theory shall hold. We will now illustrate the procedures we adopted to build the rate of return (RoR) matrix using our data for Italy.

We defined the growth rates of prices $(i p X)$ of financial assets as the rate of change in their price over the last quarter (eq. 66). The return on assets $(\mathrm{raX})$ is computed as the sum of the change in their price and the relative interest rate (eq. 67) and - for NFC shares only-we use the flow of dividends paid by NFCs relative to the existing stock of shares (eq. 68). We define the stock of each asset using the (estimated) portfolio ratios in total illiquid assets (eq. 69) and assume households to have adaptive expectations with respect to the RoR (four lags with diminishing weights, in eq. 70).

$$
\begin{aligned}
& i p X=p X / p X_{t-1}-1 \\
& r a X=d(p X) / p X_{t-1}+r X \\
& r a E N=d(p E N) / p E N_{t-1}+D I V P n f c / E N_{t-1} \\
& X=r p X \cdot F A S S_{t-1} \cdot\left(X_{t-1}\right) \\
& r a X^{e}=0.4 \cdot \operatorname{raX}_{t-1}+0.3 \cdot \operatorname{raX}_{t-2}+0.2 \cdot \operatorname{raX}_{t-3}+0.1 \cdot \operatorname{raX}_{t-4}
\end{aligned}
$$

Finally, we estimated the following system:

\section{Banks' debt instruments}

$$
\begin{aligned}
& B B h=F A S S_{t-1} \cdot\left[c 1 \cdot r a B B^{e}+c 2 \cdot r a E B^{e}+c 3 \cdot r a E N^{e}+c 4 \cdot r a B^{e}+c 5 \cdot r a F^{e}+c 6\right]+ \\
& B B h_{t-1} / F A S S_{t-2}
\end{aligned}
$$

\section{Banks' equities}

$$
\begin{aligned}
& E B_{h h}=F A S S_{t-1} \cdot\left[c 2 \cdot r a B B^{e}+c 7 \cdot r a E B^{e}+c 8 \cdot r a E N^{e}+c 9 \cdot r a B^{e}+c 10 \cdot r a F^{e}+c 11\right]+ \\
& E B_{h h, t-1} / F A S S_{t-2}
\end{aligned}
$$


Firms' equities

$$
\begin{aligned}
& E N_{h h}=F A S S_{t-1} \cdot\left[c 3 \cdot r a B B^{e}+c 8 \cdot r a E B^{e}+c 12 \cdot r a E N^{e}+c 13 \cdot r a B^{e}+c 14 \cdot r a F^{e}+\right. \\
& c 15]+E N_{h h, t-1} / F A S S_{t-2}
\end{aligned}
$$

\section{Government bonds}

$$
\begin{aligned}
& B_{h h}=F A S S_{t-1} \cdot\left[c 4 \cdot r a B B^{e}+c 9 \cdot r a E B^{e}+c 13 \cdot r a E N^{e}+c 16 \cdot r a B^{e}+c 17 \cdot r a F^{e}+\right. \\
& c 18]+B_{h h, t-1} / F A S S_{t-2}
\end{aligned}
$$

Foreign assets

$$
\begin{aligned}
& F_{h h}=F A S S_{t-1} \cdot\left[c 5 \cdot r a B B^{e}+c 10 \cdot r a E B^{e}+c 14 \cdot r a E N^{e}+c 17 \cdot r a B^{e}+c 19 \cdot r a F^{e}+\right. \\
& c 20]+F_{h h, t-1} / F A S S_{t-2}
\end{aligned}
$$

The resulting coefficients are available upon request. Most of the estimated lambdas for our RoR matrix are either nonsignificant or show the wrong sign. Nevertheless, we did find some meaningful relations: first, there is a negative relation between the RoR on government bonds and foreign assets and, secondly, a negative one between banks' obligations and banks' shares, which is however less strong. Given the result of the system estimation, we found it sensible to only endogenize the equations for the portfolio ratios ( $r p$ ) of bonds (eq. 76), banks' debt instruments (eq. 77), and foreign assets (eq. 78), and project the rest exogenously. Results are shown below.

$$
\begin{aligned}
& r p B=f\left(r a F^{e} ; r a B B^{e}\right) \\
& r p B B=f\left(A R 1,4 ; r a E B^{e} ; r a B^{e}\right) \\
& r p F=f\left(r a B^{e} ; r a F^{e}\right)
\end{aligned}
$$




\begin{tabular}{|c|c|c|}
\hline \multirow[t]{2}{*}{ Portfolio ratios } & \multirow[b]{2}{*}{ Coefficients } & \\
\hline & & \\
\hline A) Gov. bonds & & \\
\hline Expected return on foreign assets & $-0.001 * *$ & Method: OLS \\
\hline Expected return on gov. bonds & 0.001 & $\begin{array}{l}\text { Sample: } 2000 \mathrm{q} 1-2019 \mathrm{q} 1 \\
\text { Adj-R2: } 0.035\end{array}$ \\
\hline B) Banks' debt instruments & & \\
\hline AR & $0.547 * * *$ & Method: OLS \\
\hline Expected return on banks' equities & $-0.001 * *$ & Sample: $2000 q 1-2019 q 1$ \\
\hline Expected return on gov. bonds & -0.001 & Adj-R2: 0.381 \\
\hline C) Foreign assets & & \\
\hline Expected return on gov. bonds & -0.347 & $\begin{array}{l}\text { Method: OLS } \\
\text { Sample: } 2000 q 1-2019 q 1 \\
\text { Adj-R2: } 0.025\end{array}$ \\
\hline
\end{tabular}

\section{Nonfinancial Corporations}

Recall that NFCs' profits are determined residually from total profits generated in production (eq. 27).

$$
O P S_{n f c}=O P S-\left(O P S_{h h}+O P S_{f c}+O P S_{g v t}\right)
$$

Firms' primary income (eq. 79), as before, is given by adding (and subtracting) the profits originated in production $\left(O P S_{n f c}\right)$ to the incomes received (and paid) from capital. NFCs receive interest income on their stock of deposits and public debt (eq. 80), dividends from their holdings of foreign firms' shares (eq. 81), and other net capital incomes (eq. 82). They also pay interest incomes on their loans (eq. 83), dividends on the shares sold domestically and abroad (eqs. 84 and 85, respectively), ${ }^{18}$ and rent from land ownership to the government (eq. 86).

$$
\begin{aligned}
& Y P_{n f c}=O P S_{n f c}+\left(I N T R_{n f c}+F D I Y_{n f c}+K Y N E T_{n f c}\right)-\left(I N T P_{n f c}+D I V P_{n f c}+F D I Y_{\text {row }}+\right. \\
& \left.R E N T L N_{n f c}\right) \\
& I N T R_{n f c}=\left(r_{t}^{\text {deps }} \cdot D E P S_{n f c, t-1}+r_{t}^{b} \cdot B_{n f c, t-1}\right)-D I S C_{-} I N T R_{n f c} \\
& F D I Y_{n f c}=r_{t}^{f d i o} \cdot F D I O_{t-1}
\end{aligned}
$$

${ }^{18}$ With respect to dividends, we added the discrepancy from the X-12 procedure to NFC payments, $D I V P_{n f c}$. 


$$
\begin{aligned}
& K_{Y N E T_{n f c}}=K I N C O R_{n f c}+\left(R E I N V F D I_{-} R_{n f c}-R E I N V F D I_{-} P_{\text {row }}\right)-\left(R E I N V F D I_{-} P_{n f c}-\right. \\
& \text { REINVFDI_R } R_{\text {row }} \text { ) } \\
& I_{N T P_{n f c}}=r_{t}^{b l f i r m s} \cdot B L F I R M S_{t-1}-D_{I S C_{-} I N T P_{n f c}} \\
& D I V P_{n f c}=r_{t}^{e n} \cdot E N_{t-1} \\
& F D I Y_{\text {row }}=r_{t}^{\text {fdii }} \cdot F D I I_{t-1} \\
& \operatorname{RENTLN}_{n f c}=R E N T L N_{g v t}-R_{E N T L N}
\end{aligned}
$$

NFCs' disposable income (eq. 87) is equal to the sum of primary income, other current net transfers, and social contributions received, after deducting the direct taxes paid domestically and abroad (TAXPD and TAXPW, respectively) and the payments in pensions. Net current transfers are the sum of total transfers net of benefits (paid and received, eq. 88). We assume that NFCs pay direct taxes as a fixed share on their profits (eq. 89), with the amount paid abroad determined as a fixed share on the wages paid to foreigners (eq. 90) and the amounts paid domestically determined residually (eq. 91). Pension payments and social contributions are determined through exogenous shares in households' total receipts/payments (eqs. 92 and 93, respectively).

$$
\begin{aligned}
& Y D_{n f c}=Y P_{n f c}+O T C N_{n f c}+S O C C O N_{n f c}-\left(T A X P W_{n f c}+T A X P D_{n f c}+P E N S P A Y M_{n f c}\right)(87 \\
& O T C N_{n f c}=O T C N_{-} T O T_{n f c}+B E N R_{n f c}-B E N P_{n f c} \\
& T A X P_{n f c}=\theta_{n f c}^{d t} \cdot O P S_{n f c} \\
& T A X P W_{n f c}=\theta_{n}^{d t w} f c \cdot W A G E S 2 R O W \\
& T A X P D_{n f c}=T A X P_{n f c}-T A X P W_{n f c} \\
& P E N S P A Y M_{n f c}=\text { ratio }_{n f c}^{\text {pens }} \cdot P E N S P A Y M \\
& \operatorname{SOCCON}_{n f c}=\text { rationsc }_{n f c} \cdot \text { SOCCON }
\end{aligned}
$$

NFCs' savings result from the addition of the revaluations in pension entitlements to disposable income (eq. 94). The former is given by an exogenous ratio for the share of NFC payments in total payments in pensions (eq. 95).

$$
\begin{aligned}
& S A V_{n f c}=Y D_{n f c}+P E N S R_{n f c} \\
& P E N S R_{n f c}=\text { ratio }_{n f c}^{\text {pensr }} \cdot \text { PENSPAYM }
\end{aligned}
$$


Finally, to obtain the NFCs' net lending position (eq. 96), we first need to add to savings the net transfers related to other transactions in capital accounts paid by the government (eq. 97), the other net transfers (eq. 98), and the taxes on capital transactions paid domestically and abroad (eq. 99). We then need to further subtract the firms' investment in gross fixed capital (eq. 100), changes in inventories $\left(D I N V_{n f c}\right)$, and other nonproduced, nonfinancial assets. Firms investment in physical capital $\left(G F C F_{n f c}\right)$ is later split among (real) investment in machinery and nonresidential buildings through an exogenous fixed ratio in total investment, while investment in inventories is computed residually (eq. 101) by subtracting other sectors' investment from total changes in inventories.

$$
\begin{aligned}
& N E T L E N D_{n f c}=S A V_{n f c}+\left(T R K O_{-} G N+N T R K_{n f c}-T R K T A X P W_{n f c}-T R K T A X P D_{n f c}\right)- \\
& G F C F_{n f c}-D I N V_{n f c}-O T H D N A_{n f c} \\
& T R K O_{-} G N=T R K O_{-} R_{n f c} \\
& N T R K_{n f c}=-T R K O_{-} P_{n f c} \\
& T R K T A X_{-} P D_{n f c}=T R K T A X_{-} P_{n f c}-T R K T A X_{-} P W_{n f c} \\
& G F C F_{n f c}=r a t i O_{n f c}^{g f c f} \cdot\left(g f c f k_{m}+g f c f k_{n r}\right) \\
& D I N V_{n f c}=D I N V-\left(D I N V_{h h}+D I N V_{f c}+D I N V_{g v t}\right) \\
& N E T L E N D F_{n f c}=N E T L E N D_{n f c}+D I S C_{-} N E T L E N D_{n f c}
\end{aligned}
$$

Portfolio adjustments for the nonfinancial business sector are meant to determine the additional demand for credit from banks (BLFIRMS, eq. 110)-meaning that firms will first use their own funds to finance investments and take on new debt to finance the gap. On the asset side, the stock of bank deposits is modeled as a ratio to the wage bill (eq. 104). This ratio has been increasing since the start of the eurozone crisis, but it will be projected exogenously in this version of the model.

The demand for government bonds is interpreted as an additional demand for liquid assets, and it is therefore modeled with respect to the stock of deposits (eq. 105). In other words, firms demand liquid assets with respect to their current expenses on labor, splitting their liquid assets between deposits and government bonds. In principle, a higher interest rate on bonds relative to the rate on deposits should increase the share of bonds in firms' portfolio, but the data are not congruent with this, so that this ratio will also be projected exogenously. 
The flows of outgoing foreign direct investment (VFDIO) and incoming foreign direct investment (VFDII) are both projected exogenously as the result of domestic and foreign firms' strategies ruled by animal spirits (in eq. 106 and eq. 107, respectively).

Other net financial assets $\left(O N F A_{n f c}\right)$ are negative and growing in size, and therefore in the next version of the model they deserve a better treatment as additional sources of funding. For the time being, they are projected exogenously (eq. 108). Finally, new issues of equities (VEN) are projected exogenously as an autonomous decision of firms (eq. 109).

$$
\begin{aligned}
& N F A_{n f c}=N F A_{n f c, t-1}+N E T L E N D F_{n f c}+N K G A I N S_{n f c} \\
& D E P S_{n f c}=r a t i o_{n f c}^{\text {deps }} \cdot\left(W B_{t-1}\right) \\
& B_{n f c}=r a t i o_{n f c}^{B} \cdot D E P S_{n f c, t-1} \\
& F D I O=F D I O_{t-1}+V F D I O+p^{f d i o} \cdot F D I O_{t-1} \\
& F D I I=F D I I_{t-1}+V F D I I+p^{f d i i} \cdot F D I I_{t-1} \\
& O N F A_{n f c}=O N F A_{n f c, t-1}+V O N F A_{n f c}+N K G_{-} O N F A_{n f c} \\
& E N=E N_{t-1}+V E N+p^{e n} \cdot V E N_{t-1} \\
& B L F I R M S=B L F I R M S_{t-1}+\left(\Delta D E P S_{n f c}+\Delta B_{n f c}+\Delta F D I O+\Delta O N F A_{n f c}-\Delta N F A_{n f c}\right)- \\
& \Delta E N-\Delta F D I I
\end{aligned}
$$

\section{Central Bank}

The central bank only collects interest on the stocks of advances lent to banks and on the stocks of government bonds and foreign liabilities it holds (eq. 111). We assumed that all these interest streams are passed to the government sector (eq. 112) so that the net lending position of the central bank is zero.

$$
\begin{aligned}
& I N T R_{c b}=\left(r_{t}^{a d v} \cdot A D V_{t-1}+r_{t}^{b} \cdot B_{c b, t-1}+r_{t}^{f} \cdot F_{c b, t-1}\right) \\
& O T C P_{c b}=I N T R_{c b}
\end{aligned}
$$

Following the current accounting conventions, some operations made by the central bank as part of the European System of Central Banks (ESCB) are treated as operations with the rest of the world (RoW), but the monetary liabilities in Target2 appear as part of the liabilities of the national central bank. 
To model base money in a currency union, it is reasonable to assume that in normal times the demand for the monetary base, coming from households, banks, and foreign institutions, is accommodated by the central bank, as in equation (113A). The change in the monetary base would in turn be related to changes on the asset side, with the different components determined by the demand for liquidity coming from households, the reserve requirements needed by banks, and the part of external imbalances that are not covered by changes in other net assets vis-à-vis the RoW. Indeed, this is in line with the theoretical discussions of central bank monetary policy made by Godley and Lavoie (2007), Lavoie (2014), the Bank of England (McLeay, Amar, and Thomas 2014), and the ECB itself (2017).

$$
M B=M B_{h h}+M B_{f c}+M B_{T 2}
$$

In response to the Great Recession, however, the ECB started adopting "unconventional” monetary policies. Through its QE operations, the ESCB supplied central bank reserves well above the demand for liquidity stemming from the banking sector, inducing a sizable increase in base money (and excess reserves). This mechanism started with the bank refinancing operations and was further enhanced with the launch of the asset purchase programs (APPs). ${ }^{19}$ When purchasing assets, the ECB supplies reserves to the banking system and, "since banks are typically the only entities, apart from central government, that hold deposit accounts with the central bank, purchases are always settled through them, regardless of who the ultimate seller is. Thus, purchases conducted under the APP resulted in a mechanic, direct increase in base money" (European Central Bank 2017, 64). When running unconventional policies it is thus the central bank, through its operations, that determines the amount of reserves in the system, instead of them being demand-driven through the net demand for credit. Most importantly, banks can do nothing to reduce the amount of reserves. Only if banks' demand for compulsory reserves increase (because of increases in deposits) should the stock of excess reserves diminish. Therefore, the total monetary base is fully determined by central banks' decisions to purchase assets (open market operations, targeted long-term refinancing operations [TLTROs], etc.).

In the presence of QE, thus, it is sensible to split the monetary base on the asset side of banks' balance sheets $\left(M B_{f c}\right)$ into two components (eq. 140). The first one is the reserve requirement ( $M B_{f c}^{r r}$, eq. 141), which varies with the reserve ratio to deposits $\left(\alpha_{1}^{r e s}\right)$ and the share of sight deposits in total deposits

${ }^{19}$ The main programs adopted by the ECB consisted of two rounds of long-term refinancing operations (LTRO and TLTRO) and the APP, which substantially increased with the launch of the Public Sector Purchase Program (PSPP). 
$\left(\alpha_{2}^{\text {sdeps }}\right)$. The second component is in turn represented by residual (excess) liquidity $\left(M B_{f c}^{e r}\right)$. While on the one hand this may have been driven by the demand for liquidity connected to financial instability, on the other it has been the outcome of unconventional monetary policy. We therefore model the “excess" stock of monetary base as the residual in the banks' portfolio adjustment.

$$
M B_{f c}=M B_{f c}^{r r}+M B_{f c}^{e r}
$$

where

$$
M B_{f c}^{r r}=\alpha_{1}^{r e s} \cdot \alpha_{2}^{s d e p s} \cdot D E P S
$$

Thus, given that the ESCB has been purchasing Treasuries and other assets from the financial system in exchange for monetary base, so that some components of $(M B)$ are the mirror of QE operations rather than those arising from the demand for liquidity, we tentatively assume that the end-of-period stock of monetary base is determined by the asset side in the central bank's balance sheet (eq. 113), with net central bank financial assets $\left(N F A_{c b}\right)$ determined exogenously, but taking into account net capital gains (eq. 114).

The value of gold reserves is computed considering the international price of gold, while the changes in the stock (i.e., net acquisition of gold) are treated as exogenous, and are relatively rare (eq. 115). A discrepancy $\left(D I S C_{-} V G O L D\right)$ is needed because the revaluation of the stock of gold is not exactly equal to the theoretical estimate.

Changes in central bank advances (eq. 116) have been split into two components to better differentiate monetary operations and to disentangle the ECB's role from that of the Italian central bank. We subtract QE-related operations (mainly LTRO, DADVQE1) from total advances to get the BoI's ordinary operations (DADVNET), and both will be exogenously determined in the model.

We assume that the central bank's acquisition of government bonds (eqs. 117 and 118) is given partly by the second phase of the QE program $(D B C B Q E 2)$ and, for the rest (DBCBNET), by the central bank's standard operations, with both components determined exogenously. This assumption does not imply that the central bank is purchasing Treasuries on the primary market, nor that it is controlling the 
interest rate on Treasuries, which is governed by another equation in the model - one that links the interest rate on Italian bonds to the German rate, plus a spread that depends on financial conditions.

The net demand for foreign financial assets from the central bank ( $V F_{c b}$, eq. 119) is currently left exogenous, as well as the net change in other financial assets (VONF $A_{C B}$, eq. 120), while the end-ofperiod stocks will be given by the usual accounting relationship.

$$
\begin{aligned}
& M B=\left(G O L D+B_{c b}+F_{c b}+O N F A_{c b}+A D V\right)-N F A_{c b} \\
& N F A_{c b}=N F A_{c b, t-1}+N E T L E N D F_{c b}+N K G A I N S_{c b} \\
& G O L D=G O L D_{t-1}+V G O L D+p^{g o l d} \cdot G O L D_{t-1}+D I S C_{-} V G O L D \\
& A D V=A D V_{t-1}+D A D V N E T+D A D V Q E 1 \\
& V B_{c b}=D B C B N E T+D B C B Q E 2 \\
& B_{c b}=B_{c b, t-1}+V B_{c b}+p^{b} \cdot B_{c b, t-1}+D I S C_{-} V B_{c b} \\
& F_{c b}=F_{c b, t-1}+V F_{c b}+p^{f} \cdot F_{c b, t-1} \\
& O N F A_{c b}=O N F A_{c b, t-1}+V O N F A_{c b}+N K G_{-} O N F A_{c b}
\end{aligned}
$$

\section{Financial Corporations}

Financial corporations' gross operating surplus is determined by their share in total profits $\left(O P S_{f c}\right.$, eq. 25). Adding net income from capital ${ }^{20}$ yields primary income $\left(Y P_{f c}\right.$, eq. 121). Banks collect interest income (eq. 122) on the outstanding stocks of loans issued to the private sector, the public debt held and the stock of foreign assets, dividends (eq. 123) on their stock of NFCs' (domestic) shares, and other net capital incomes (net of FDIs, in eq. 124). They also pay interest income (eq. 125) on central bank advances, deposits, and the stock of liabilities issued. Finally, they pay dividends on their issued shares (eq. 126).

$$
\begin{aligned}
& O P S_{f c}=\pi_{f c} \cdot O P S \\
& Y P_{f c}=O P S_{f c}+\left(I N T R_{f c}+D I V R_{f c}+K Y N E T_{f c}\right)-\left(I N T P_{f c}+D I V P_{n f c}\right)
\end{aligned}
$$

\footnotetext{
${ }^{20}$ When adjusting the series, we decided to add the discrepancies of the X-12 procedure to the interest received by financial corporations $\left(I N T R_{f c}\right)$. This is so because financial institutions get almost half of the total interests paid and one should always try to get these discrepancies away from series that will enter the behavioral specifications' estimates, in particular those regarding the household and external sectors.
} 


$$
\begin{aligned}
& I N T R_{f c}=\left(r_{t}^{b l c c} \cdot B L C C_{t-1}+r_{t}^{b l m o} \cdot B L M O_{t-1}+r_{t}^{b l f i r m s} \cdot B L F I R M S_{t-1}+r_{t}^{b} \cdot B_{f c, t-1}+r_{t}^{f} .\right. \\
& \left.F_{f c, t-1}\right)-D I S C_{-} I N T R_{f c} \\
& D I V R_{f c}=\left(r^{e n} \cdot E N_{f c, t-1}\right)+D I S C_{-} D I V R_{f c} \\
& K Y N E T_{f c}=K I N C O_{-} R_{f c}-K I N C O_{-} P_{f c}+R E I N V F D I_{-} R_{f c}-R E I N V F D I_{-} P_{f c} \\
& I N T P_{f c}=\left(r_{t}^{a d v} \cdot A D V_{t-1}+r_{t}^{d e p s} \cdot D E P S_{t-1}+r_{t}^{b b} \cdot B B_{t-1}\right)-D I S C_{-} I N T P_{f c} \\
& D I V P_{f c}=\left(r^{e b} \cdot E B_{t-1}\right)
\end{aligned}
$$

Adding the other current net transfers $\left(O T C N_{f c}\right.$, eq. 128) and social contributions received (eq. 129) and deducting the direct taxes paid and pension payments (eq. 130 and 131, respectively) yields banks' disposable income (eq. 127).

$$
\begin{aligned}
& Y D_{f c}=Y P_{f c}+\left(\operatorname{OTCN}_{f c}+\operatorname{SOCCON}_{f c}\right)-\left(T_{A X} P_{f c}+P E N S A P A Y M_{f c}\right) \\
& \operatorname{OTCN}_{f c}=O T C N_{-} T O T_{f c}+B E N R_{f c}-B E N P_{f c} \\
& \operatorname{SOCCON}_{f c}=\text { ratio }_{f c}^{s c} \cdot S O C C O N \\
& \operatorname{TAXP}_{f c}=\theta_{f c}^{d t} \cdot O P S_{f c} \\
& \operatorname{PENSPAYM}_{f c}=\text { ratio }_{f c}^{\text {pens }} \cdot \text { PENSPAYM }
\end{aligned}
$$

Financial corporations' savings are the result of the addition of the revaluations in pension entitlements to disposable income $\left(S A V_{f c}\right.$, eq. 132). The variations in pension entitlements are given by an exogenous ratio times the total payments in pensions (eq. 133).

$$
\begin{aligned}
& S A V_{f c}=Y D_{f c}+P E N S R_{f c} \\
& P_{E N S R_{f c}}=\text { ratio }_{f c}^{\text {pensr }} \cdot \text { PENSPAYM }
\end{aligned}
$$

Finally, banks' net lending position (NETLEND $D_{f c}$ in eq. 134) is obtained by adding (subtracting) the transactions related to taxes and transfers on capital accounts (TRKTAXP $P_{f c}$ and TRKO_GF, in eqs. 135 and 136) and subtracting investments in real assets, split as usual between gross fixed capital formation $\left(G F C F_{f c}\right)$, changes in inventories $\left(D I N V_{f c}\right)$, and the acquisitions of nonproduced, nonfinancial assets $\left(O T H D N A_{f c}\right)$. Banks' investment in machinery and nonresidential dwellings are determined by an exogenous ratio (eq. 137), while the changes in inventories depends on exogenous shares in total 
changes in inventories (eq. 138). Recall that we net out the net lending position of the central bank from the accounts of monetary financial institutions (eq. 139).

$$
\begin{aligned}
& N E T L E N D_{f c}=S A V_{f c}+\left(T R K O_{-} G F+N T R K_{f c}-T R K T A X P_{f c}\right)-G F C F_{f c}-D I N V_{f c}- \\
& O T H D N A_{f c} \\
& T R K O_{-} G F=T R K O_{-} R_{f c} \\
& N T R K_{f c}=-T R K O_{-} P_{f c} \\
& G F C F_{f c}=\text { ratio }_{f c}^{g f c f} \cdot\left(g f c f_{-} m+g f c f_{-} n r\right) \\
& \operatorname{DINV}_{f c}=\text { ratio }_{F C}^{\text {dinv }} \cdot \operatorname{dinv} \\
& N E T L E N D F_{f c}=N E T L E N D_{f c}+\operatorname{DISC}_{-} N E T L E N D_{f c}-N E T L E N D F_{c b}
\end{aligned}
$$

We follow Godley and Lavoie (2007) in assuming that banks fulfil the demand for loans from household and nonfinancial firms and adjust their level of reserves accordingly, with the central bank accommodating. The model becomes more complex when QE starts, since banks will adapt their portfolio whenever cheap credit is available from central banks' QE operations.

As we said above, the monetary base on the asset side of banks' balance sheets $\left(M B_{f c}\right)$ is split into two components (eq. 140): the reserve requirement $\left(M B_{f c}^{r r}\right)$ - which varies with the reserve ratio to deposits $\left(\alpha_{1}^{r e s}\right)$ and the share of sight deposits on total deposits ( $\alpha_{2}^{r r}$, eq. 141) — and the residual liquidity $\left(M B_{f c}^{e r}\right)$. Residual liquidity may be driven, on the one hand, by the demand for excess liquidity connected to financial instability, but on the other it has been the outcome of unconventional monetary policy (QE). As the ECB buys government bonds and other financial assets from banks in exchange for liquidity, the banking sector as a whole cannot help but accumulate such liquidity. We therefore model the "excess" stock of monetary base $\left(M B_{f c}^{e r}\right)$ as the residual in banks' portfolio adjustment (eq. 142). As discussed above, this increase in excess reserves translates mechanically into a worsening of the overall Target2 balance, since most of QE operations involve cross-border transactions.

As discussed above, consumer credit, mortgages, and loans to firms are all supplied by banks on demand. For firms' equities (eqs. 143 and 144), we assume that the financial sector is the residual buyer for the new emissions, while the evolution of the stock is linked to our spread measure. However, this has no implication on how the market price of equities is determined in the model. The issues of 
new bank equities $(V E B)$, in turn, are projected exogenously as an independent decision of banks (eq. 145 ), and we assumed that the supply of equities is matched by households' demand.

We assume banks to clear the market for government bonds (eq. 147). It should be noted, however, that the vast majority of new bonds have been purchased by the ECB through its QE operations, and this situation will last until the program ends - at least, as far as June 2022 —implying that, in the current state of affairs, there is not any market to clear. With respect to the demand for foreign assets ( $F_{f c}$, eq. 148), we model the flow $\left(V F_{f c}\right.$, eq. 149) as a function of the interest rate on government bonds $\left(r^{b}\right)$ and the spread between Italian and German Treasuries (SPREAD), the (changes in) exchange rate against the US\$ ( $x r^{i t \_u s}$ ), and the flow of interest income paid by the foreign sector relative to the stock of assets.

Finally, as for all other sectors, the net change in other financial assets $\left(V O N F A_{f c}\right)$ will be left exogenous, and the end-of-period stocks will be given by the usual accounting relationship (eq. 150).

$$
\begin{aligned}
& M B_{f c}=M B_{f c}^{r r}+M B_{f c}^{e r} \\
& M B_{f c}^{r r}=\alpha_{1}^{r e s} \cdot \alpha_{2}^{s d e p s} \cdot D E P S \\
& M B_{f c}^{e r}=\Delta\left(N F A_{f c}\right)-\Delta\left(B L C C+B L M O+B L F I R M S+B_{f c}+E N_{f c}+F_{f c}+O N F A_{f c}\right)+ \\
& \Delta\left(F C_{-} l i a b\right)-\Delta M B_{f c}^{r r} \\
& V E N_{f c}=V E N-\left(V E N_{h h}+V E N_{g v t}\right) \\
& E N_{f c}=f(S P R E A D) \\
& E B=E B_{t-1}+V E B+p^{e b} \cdot E B_{t-1} \\
& B_{f c}=B_{f c, t-1}+V B_{f c}+p^{b} \cdot B_{f c, t-1} \\
& V B_{f c}=V B-\left(V B_{h h}+V B_{n f c}+V B_{r o w}+V B_{c b}\right) \\
& F_{f c}=F_{f c, t-1}+V F_{f c}+p^{f} \cdot F_{f c, t-1}+D I S C_{-} V F_{f c} \\
& V F_{f c}=f\left(r^{b}, S P R E A D, x r^{i t \_u s}, \frac{I N T P_{f c, t-1}}{F_{t-1}}\right) \\
& O N F A_{f c}=O N F A_{f c, t-1}+V O N F A_{f c}+N K G_{-} O N F A_{f c}
\end{aligned}
$$




\begin{tabular}{|c|c|c|}
\hline \multicolumn{3}{|l|}{$\begin{array}{l}\text { Banks' demand for foreign } \\
\text { assets }\end{array}$} \\
\hline eq. 149 & Coefficients & \\
\hline Interest rate on gov. bonds & $-0.021 * * *$ & Method: OLS \\
\hline Exchange rate vs. US\$ & 0.030 & Sample: $1999 q 2-2019 q 1$ \\
\hline Interest incomes paid & $-0.076^{* * *}$ & Adj-R2: 0.473 \\
\hline Spread & $0.010 * * *$ & \\
\hline
\end{tabular}

\section{Government}

The public sector income from production (eq. 151) is the sum of the indirect taxes collected and gross operating surplus (eq. 26) minus subsidies to production. Indirect taxes and subsidies paid by the government are computed residually from total payments after deducting foreign institutions' receipts (eqs. 29 and 31).

$$
\begin{aligned}
& I N C P_{g v t}=I N D T_{g v t}-S U B S_{g v t}+O P S_{g v t} \\
& O P S_{g v t}=\pi_{g v t} \cdot O P S \\
& I N D T_{g v t}=I N D T A X-I N D T_{\text {row }} \\
& S U B S_{g v t}=S U B S-S U B S_{\text {row }}
\end{aligned}
$$

To incomes from production, we add the transaction in capital incomes to get to government primary income (eq. 151). The government collects interest income on its stock of deposits, dividends from domestic shares held, and rental incomes from the private nonfinancial sector (eqs. 153 through 155) and pays interest on public debt to all other sectors (eq. 156).

$$
\begin{aligned}
& Y P_{g v t}=\left(O P S_{g v t}+I N D T_{g v t}\right)-\left(S U B S_{g v t}\right)+\left(I N T R_{g v t}+D I V R_{g v t}+R E N T L N_{g v t}\right)- \\
& \left(I N T P_{g v t}\right) \\
& I N T R_{g v t}=\left(r_{t}^{d e p s} \cdot D E P S_{g v t, t-1}\right)-D I S C_{-} I N T R_{g v t} \\
& D I V R_{h h}=\left(r_{t}^{e n} \cdot E N_{g v t, t-1}\right)+D I S C_{-} D I V R_{g v t} \\
& \operatorname{RENTLN}_{g v t}=R E N T L N_{-} P_{n f c}+R E N T L N_{-} P_{h h} \\
& I N T P_{g v t}=\left(r_{t}^{b} \cdot B_{t-1}\right)-D I S C_{-} I N T P_{g v t}
\end{aligned}
$$


Government disposable income (eq. 157) is given by adding to primary income the direct taxes received (eq. 158), social contributions (determined residually from other sector receipts in eq. 159), and the sum of other current net transfers (eq. 161), and central bank seignorage (eq. 112), and finally deducting pension payments (eq. 160).

$$
\begin{aligned}
& Y D_{g v t}=Y P_{g v t}+T A X N R_{g v t}+S O C C O N_{g v t}-P E N S P A Y M_{g v t}+\left(O T C N_{g v t}+O T C P_{c b}\right)(156 \\
& T A X N R_{g v t}=\left(T A X P_{h h}+T A X P D_{n f c}+T A X P_{f c}+T A X P_{\text {row }}\right)+D I S C_{-} T A X \\
& \operatorname{SOCCON}_{\mathrm{gut}}=\operatorname{SOCCON}-\left(\operatorname{SOCCON}_{n f c}+\operatorname{SOCCON}_{f c}\right) \\
& \text { PENSPAYM } M_{\text {gvt }}=\theta^{\text {pens }} \cdot W A G E U \cdot R E T I R E D \\
& O T C N_{g v t}=O T C N_{-} T O T_{g v t}+\left(B E N R_{g v t}-S O C C O N\right)-\left(B E N P_{g v t}-P E N S P A Y M\right)(160 \\
& O T C P_{c b}=I N T R_{c b}
\end{aligned}
$$

Public sector savings (eq. 161) are the result of what is left of disposable income after the outlays in collective and individual consumption (eqs. 162 and 163), which are determined as a fixed share in (real) total government expenditures.

$$
\begin{aligned}
& \operatorname{SAV}_{g v t}=Y D_{g v t}-\left(\text { CONSCOLL }_{g v t}+\operatorname{CONSIND}_{g v t}\right) \\
& \text { CONSCOLL }_{g v t}=\eta_{g v t}^{c c} \cdot G K \\
& \operatorname{CONSIND}_{g v t}=\eta_{g v t}^{i c} \cdot G K
\end{aligned}
$$

Finally, the net lending position of the public sector is, as before, the difference between savings and investments (eq. 164), taking into account transfers and taxes on capital account (eqs. 165 to 169), as well as government investments (eq. 170) and changes in inventories (eq. 171), which are both determined by exogenous ratios.

$$
\begin{aligned}
& \text { NETLEND } D_{g v t}=S A V_{g v t}+\left(T R K T A X_{-} R_{g v t}+N T R K_{g v t}+T R K O_{-} W G-T R K O_{-} G N-\right. \\
& \left.T R K O_{-} G F\right)-G F C F_{g v t}-D I N V_{g v t}-O T H D N A_{g v t} \\
& T R K T A X_{-} R_{g v t}=\left(T R K T A X_{-} P_{h h}+T R K T A X_{-} P D_{n f c}+T R K T A X_{-} P_{f c}\right) \\
& N T R K_{g v t}=\left(T R K O_{-} R_{g v t}-T R K O_{-} G W\right)-\left(T R K O_{-} P_{g v t}-T R K O_{-} G N-T R K O_{-} G F\right)(166 \\
& T R K O_{-} W G=T R K O_{-} P_{g v t}
\end{aligned}
$$




$$
\begin{aligned}
& T R K O_{-} G N=T R K O_{-} R_{n f c} \\
& T R K O_{-} G F=T R K O_{-} R_{f c} \\
& G F C F_{g v t}=r a t i o_{g v t}^{g f c f} \cdot G F C F_{G} \\
& D I N V_{g v t}=r a t i o_{g v t}^{d i v v} \cdot d i n v \\
& N E T L E N D F_{g v t}=N E T L E N D_{g v t}+\text { DISC_NETLEND } D_{g v t}
\end{aligned}
$$

When compared to those discussed above, the government sector's financial operations are quite straightforward. Indeed, the government holds deposits, mainly to pay out wages to public employees, and the flows are estimated as a function of government expenditures over deposits (eqs. 173 and 174). ${ }^{21}$ We assumed that the government buys all the residual shares of domestic firms (eqs. 175 and 176) while the demand for other net financial assets are, as usual, left exogenous (eq. 177). It issues new bonds to cover the deficit (eq. 178).

$$
\begin{aligned}
& D E P S_{g v t}=D E P S_{g v t, t-1}+V D E P S_{g v t}+D E P S_{-} W O_{g v t} \\
& V D E P S_{g v t}=f(G) \\
& V E N_{g v t}=V E N-\left(V E N_{h h}+V E N_{f c}\right) \\
& E N_{g v t}=E N_{g v t, t-1}+V E N_{g v t}+p^{e n} \cdot E N_{g v t, t-1}+D I S C_{-} V E N_{g v t} \\
& O N F A_{g v t}=O N F A_{g v t, t-1}+V O N F A_{g v t}+N K G_{-} O N F A_{g v t} \\
& V B=-N E T L E N D F_{g v t}+V D E P S_{g v t}+V E N_{g v t}+V O N F A_{g v t}
\end{aligned}
$$

\section{The Rest of the World}

The RoW collects wages and incomes from trade and indirect taxes ${ }^{22}$ (eqs. 179, 180, and 28), and also capital incomes in the form of interest (eq. 181), returns from FDI (eq. 86), and other capital incomes (eq. 182), while it pays interests on the issued liabilities (eq. 183) and dividends in the forms of returns on FDI (eq. 82).

\footnotetext{
${ }^{21}$ We computed an exogenous component for deposits write-offs to offset the discrepancies between the flow and the stock measures.

${ }^{22}$ Paid only by NFCs.
} 


$$
\begin{aligned}
& Y P_{\text {row }}=\left(M G S+X G S+D S I C_{-} T R A D E\right)+\left(W A G E S 2 R O W+I N D T_{\text {row }}\right)+\left(I N T R_{\text {row }}+\right. \\
& \left.F D I Y_{\text {row }}+K Y N E T_{\text {row }}\right)-\left(I N T P_{\text {row }}+F D I Y_{n f c}\right) \\
& W A G E S 2 R O W=W B-W A G E S \\
& I N D T_{\text {row }}=\theta^{i w} \cdot I N D T A X \\
& I N T R_{\text {row }}=\left(r_{t}^{\text {deps }} \cdot D E P S_{\text {row }, t-1}+r_{t}^{b} \cdot B_{\text {row }, t-1}\right)-D I S C_{-} I N T R_{\text {row }} \\
& F D I Y_{\text {row }}=D I V R_{\text {row }}+R E I N V F D I_{-} R_{\text {row }} \\
& K Y N E T_{\text {row }}=K I N C O R_{\text {row }}-K I N C O P_{\text {row }}+D I V R_{n f c}-D I V P_{n f c} \\
& I N T P_{\text {row }}=\left(r_{t}^{f} \cdot F_{t-1}\right)-D I S C_{-} I N T P_{\text {row }} \\
& F D I Y_{\text {nfc }}=r_{t}^{\text {fdii }} \cdot F D I I_{t-1}
\end{aligned}
$$

To primary incomes, we add the incomes from taxation (eqs. 90 and 185), the other transfers in the current account (eq. 186), and the social contributions received (eq. 187), subtracting the pension payments (eq. 188) to yield disposable income (eq. 184). Net lending (eq. 190), as usual, is determined by adding to the RoW's saving (eq. 189), the taxes paid and received, and the other transfers on capital accounts.

$$
\begin{aligned}
& Y D_{\text {row }}=Y P_{\text {row }}+\left(T A X P W_{\text {nfc }}-T A X P_{\text {row }}-P E N S P A Y M_{\text {row }}\right)+O T C N_{\text {row }}+S O C C O N_{\text {row }} \\
& T A X P W_{n f c}=\theta_{n}^{d t w} f c \cdot W A G E S 2 R O W \\
& T A X P_{\text {row }}=\theta_{\text {row }}^{d} \cdot W A G E S F R O W \\
& O T C N_{\text {row }}=-\left(\text { OTCN }_{h h}+O T C N_{\text {nfc }}+O T C N_{f c}+O T C N_{\text {gvt }}\right) \\
& \text { SOCCON }_{\text {row }}=\text { ratio }^{\text {SC }} \cdot \text { SOCCON } \\
& P E N S P A Y M_{\text {row }}=\text { ratio }_{\text {row }}^{\text {pens }} \cdot \text { PENSPAYM } \\
& S A V_{\text {row }}=Y D_{\text {row }} \\
& N E T L E N D_{\text {row }}=S A V_{\text {row }}+\left(T R K T A X_{-} P W_{\text {nfc }}+N T R K_{\text {row }}-T R K O_{-} W G\right)-O T H D N A_{\text {row }} \\
& N E T L E N D F_{\text {row }}=N E T L E N D_{\text {row }}+\text { DISC_NETLEND } D_{\text {row }}
\end{aligned}
$$


At this stage of model development, we decided to treat the foreign sector as the residual buyer for some of our assets. This aspect will have to be improved in future releases. The RoW holds domestic banks' deposits as liquidity for trade (eq. 192). It buys the residual supply of domestic banks' securities (eq. 193), while the acquisition of new government bonds is currently left exogenous (eq. 194). Moreover, we assumed that the demands for foreign assets coming from the domestic sectors are completely matched (eq. 195).

Finally, the RoW's other net financial assets are determined as the sum of all other sectors (eq. 196), while the buffer stock is represented here by the Target 2 balance (eq. 197).

$$
\begin{aligned}
& D E P S_{\text {row }}=\text { ratio } o_{\text {row }}^{\text {deps }} \cdot(X G S+M G S) \\
& B B_{\text {row }}=B B-B B_{\text {hh }} \\
& V B_{\text {row }}=d\left(B_{\text {row }}-p^{b} \cdot B_{\text {row }, t-1}\right)-D I S C_{-} V B_{\text {row }} \\
& V F=V F_{\text {hh }}+V F_{f c}+V F_{c b} \\
& O N F A_{\text {row }}=-\left(O N F A_{\text {hh }}+O N F A_{\text {nfc }}+O N F A_{f c}+O N F A_{c b} O N F A_{\text {gvt }}\right) \\
& M B_{T 2}=N F A_{\text {row }}-\left(D E P S_{\text {row }}+B B_{\text {row }}+B_{\text {row }}+F D I I+O N F A_{\text {row }}\right)+(G O L D+F D I O+F)
\end{aligned}
$$

\section{Trade}

We now introduce the trade block of the model. We model imports of goods and services ${ }^{23}$ with an error correction model (ECM) depending in the long run on domestic demand and relative prices, and in the short run on domestic demand only. We added a dummy for a structural break occurring in 2009Q2 (eq. 198). With respect to exports, in light of the importance that export dynamics have always had for the Italian economy's performance, we decided to model separately the exports of goods $(x g)$ and services (xs) (eqs. 199 and 200).

$$
\begin{aligned}
& \text { MGSK }=\mathrm{f}\left(G D P K ; \frac{p^{m g s}}{p^{g d p}}\right) \\
& X G K=f\left(L W D E M ; x r^{i t \_u s e} ; L P L C ; p^{g d p}\right) \\
& X S K=f\left(L W D E M ; x r^{\text {it_use }} ; p^{g d p}-L P L C ; p^{g d p}\right)
\end{aligned}
$$

\footnotetext{
${ }^{23}$ Recall that variables ending with $k$ are expressed at constant 2010 prices.
} 


\begin{tabular}{|c|c|c|}
\hline Imports of goods and services & & \\
\hline eq. 198 & Long-run coefficients & \\
\hline Real GDP & $2.388 * * *$ & Method: OLS \\
\hline Real GDP after 2009Q2 & $2.400 * * *$ & Sample: 1996q4-2019q2 \\
\hline Relative prices & $\begin{array}{l}-0.671 * * * \\
\text { Short-run coefficients }\end{array}$ & Adj-R2: 0.611 \\
\hline Real GDP growth & $2.691 * * *$ & \\
\hline
\end{tabular}

\begin{tabular}{|c|c|c|}
\hline \multicolumn{3}{|l|}{ Exports of goods } \\
\hline eq. 199 & Long-run coefficients & \\
\hline World demand & $1.224 * * *$ & Method: OLS \\
\hline Exchange rate & $0.154 *$ & Sample: 1996q3-2019q2 \\
\hline & Short-run coefficients & Adj-R2: 0.712 \\
\hline Growth in world demand & $4.328 * * *$ & \\
\hline Growth in domestic prices & $-0.574 * *$ & \\
\hline Growth in foreign prices & 0.486 & \\
\hline Exchange rate & $0.094 * * *$ & \\
\hline
\end{tabular}

\begin{tabular}{|c|c|c|}
\hline \multicolumn{3}{|l|}{ Exports of services } \\
\hline eq. 200 & Long-run coefficients & \\
\hline World demand & $2.806 * * *$ & Method: OLS \\
\hline Exchange rate & $0.010 *$ & Sample: 1996q2-2019q2 \\
\hline Domestic prices & $-1.711 * * *$ & Adj-R2: 0.499 \\
\hline Foreign prices & $-1.106^{* * *}$ & \\
\hline & Short-run coefficients & \\
\hline Growth in world demand & $4.049 * * *$ & \\
\hline
\end{tabular}

Using the real exchange rate in our export equations does not provide useful results, since exports seem to react differently to changes in domestic prices, foreign prices, or the euro/dollar exchange rate. The reaction of export of services to foreign prices is unexpected and will require further investigation for a better specification in future work.

The imports deflator (eq. 201) is modeled as an ECM depending on foreign prices in local currencies (LPLC) and the exchange rate against the US\$. We find a structural break in the growth rate of import prices with the introduction of the euro in 1999 and we use a dummy variable for 2009Q1 to account for the extraordinary drop in trade after the financial crisis; both breaks are both found to be statistically significant. 


$$
p^{m g s}=f(l p l c ; x r ; d u m 2009 q 1)
$$

\begin{tabular}{|c|c|c|}
\hline Imports deflator & & \\
\hline eq. 201 & Long-run coefficients & \\
\hline Foreign prices & $0.735 * * *$ & Method: OLS \\
\hline Exchange rate vs. US\$ & $\begin{array}{l}-0.216 \\
\text { Short-run coefficients }\end{array}$ & $\begin{array}{l}\text { Sample: } 1996 \mathrm{q} 3-2019 \mathrm{q} 2 \\
\text { Adj-R2: } 0.379\end{array}$ \\
\hline $\begin{array}{l}\text { Foreign prices } \\
\text { Exchange rate before } 1999\end{array}$ & $\begin{array}{l}2.208 * * \\
-0.088\end{array}$ & \\
\hline
\end{tabular}

Since we model exports of goods separately from that of services, we need to obtain their deflators. ${ }^{24}$ Starting from the former, the export deflator for goods (eq. 202) is modeled as an ECM depending on unit labor costs (ULC) in the long-run and on foreign prices only in the short run. Contrarily, we find that the deflator of exports of services (eq. 203) depends solely on foreign prices in the long run, while it also depends on the exchange rate in the short run, with a significant effect following the euro's introduction.

$$
\begin{aligned}
& p^{x g}=f\left(\frac{\text { WAGEU }}{\text { PROD }} ; \text { LPLC }\right) \\
& p^{x s}=f\left(\text { LPLC; } ; r^{\text {it_use }}\right)
\end{aligned}
$$

\begin{tabular}{|c|c|c|}
\hline Exports deflator & & \\
\hline eq. 202 & Long-run coefficients & \\
\hline Unit labor cost & $0.423 * * *$ & Method: OLS \\
\hline & Short-run coefficients & Sample: 1999q2-2019q2 \\
\hline Foreign prices & $1.428 * * *$ & Adj-R2: 0.352 \\
\hline eq. 203 & Long-run coefficients & Method: OLS \\
\hline Foreign prices & $\begin{array}{l}0.807 * * * \\
\text { Short-run coefficients }\end{array}$ & $\begin{array}{l}\text { Sample: } 1997 \mathrm{q} 2-2019 \mathrm{q} 2 \\
\text { Adj-R2: } 0.378\end{array}$ \\
\hline $\begin{array}{l}\text { Foreign prices } \\
\text { Exchange rate }\end{array}$ & $\begin{array}{l}1.110 \\
-0.081\end{array}$ & \\
\hline
\end{tabular}

Finally, the index for Italian competitiveness (eq. 204) is found to depend on the same index for Germany and for the deflator of exports of goods, in both the short and long run, underlining the close relation between the two countries and their interconnections in the industrial value chain.

\footnotetext{
${ }^{24}$ It is worth noting, however, that the price elasticities that we found need more in-depth analysis.
} 


$$
\operatorname{comp}^{i t}=f\left(\operatorname{comp}^{\text {de }} ; p x g\right)
$$

We mention this variable for completeness, since we tried to use it as an alternative to an endogenous measure of the real exchange rate, but it is not operational in the current version of the model.

\section{Labor Market}

The treatment of the labor market is rather rudimentary at this stage.

Population $(P O P)$ is projected exogenously, and the share of the working-age population is obtained through exogenous parameters, identifying those below the working age (pop014, eq. 205) and retired people (retired, eq. 206). Retired people are estimated from the difference between the population above 64, and those above 64 who are reported as employed or unemployed.

$$
\begin{aligned}
& \text { pop014 }=\text { par }^{\text {ypop }} \cdot P O P \\
& \text { retired }=\text { par }^{\text {retired }} \cdot P O P
\end{aligned}
$$

The size of the labor force ( $L F$, eq. 207) is given by an exogenous participation rate. Our attempts to model the participation rate as a function of the state of the business cycle or other labor market indicators has not been successful yet. The participation rate has been increasing over time since the 1980s, from around 58 percent to the current 66 percent, but the increase in the employment rate has not been as substantial.

Employment (EMP, eq. 208) is determined from a simple relation to real GDP through average labor productivity (PROD, eq. 209), which we model as a function of the business cycle and of part-time workers' share in the labor force. For both the long- and short-run specifications we found the presence of a structural break related to the GFC (in 2008Q3).

$$
\begin{aligned}
& L F=\text { partrate } \cdot(P O P-\text { pop } 014-\text { retired }) \\
& E M P=G D P K / P R O D \\
& P R O D=f\left(G D P K ; \text { ratio }^{n p t i} ; P R O D ; P R O D \_C E ; " 2008 q 3^{\prime \prime}\right)
\end{aligned}
$$




\begin{tabular}{|c|c|c|}
\hline Labor productivity & & \\
\hline eq. 209 & Long-run coefficients & \\
\hline Real GDP & $0.241 * * *$ & Method: VEC+OLS \\
\hline Ratio of part-time workers & $-0.372 * * *$ & $\begin{array}{l}\text { Sample: } 1999 \mathrm{q} 1-2019 \mathrm{q} 2 \\
\text { Adj-R2: } 0.331\end{array}$ \\
\hline & Short-run coefficients & \\
\hline Error correction term & $-0.127 * * *$ & \\
\hline Lagged endogenous & $0.435 * * *$ & \\
\hline 2018 dummy & $-0.006^{* * *}$ & \\
\hline
\end{tabular}

Unemployment (UNEMP, eq. 210) is thus a residual, and the unemployment rate (ur, eq. 211) follows. We also compute the U6 measure of unemployment (ur6, eq. 213) by considering those marginally attached to the labor force (LFP, eq. 212) and those working part-time for economic reasons (NPTI, eq. 214). While the first category is left exogenous at this stage of model development, we model the ratio of part-time workers in the labor force as a function of the business cycle and the unemployment rate (eq. 215). This variable enters both our equation for the extended unemployment rate, but also in that of productivity, so that increases in labor market fragmentation will translate into lower employment.

$$
\begin{aligned}
& U N E M P=L F-E M P \\
& U R=U N E M P / L F \\
& L F P=\frac{L F \cdot \text { ratiolfp }}{\left(1-\text { ratio }^{l f p}\right)} \\
& U R 6=\frac{(U N E M P+L F P+N P T I)}{(L F+L F P)} \\
& N P T I=\text { ratio }^{\text {npti }} \cdot \text { EMP } \\
& \text { ratio }^{\text {npti }}=f\left(U R ; \text { TREND; } " 2015 q 3^{\prime \prime}\right)
\end{aligned}
$$

\begin{tabular}{|c|c|c|}
\hline $\begin{array}{l}\text { Ratio of part-time workers in } \\
\text { labor force }\end{array}$ & & \\
\hline eq. 215 & Long-run coefficients & \\
\hline Unemployment rate & $0.554 * * *$ & Method: OLS \\
\hline Trend & $0.001 * * *$ & Sample: $2000 \mathrm{q} 1-2019 \mathrm{q} 2$ \\
\hline 2015 dummy & $0.024 * * *$ & Adj-R2: 0.499 \\
\hline
\end{tabular}

The level of employment, together with the average wage (wageu), determines the wage bill ( $W B$, eq. 216). The average wage, finally, is estimated as a function of domestic and foreign prices (through the imports deflator) and the past unemployment rate (eq. 217). Two dummies for 2003Q3 and 2005Q4, 
are introduced to consider two outliers (upward jumps in wages). The long-run elasticity of nominal wages to prices is one, ${ }^{25}$ while import prices do not seem to have a long-run impact. An increase in the unemployment rate is found to have an impact on the level of wages (rather than on wage inflation, as in the Phillips curve). The short-run specification needs to be investigated further, since we find a negative short-run impact of price inflation on wage inflation.

$$
\begin{aligned}
& W B=\text { wageu } \cdot E M P \\
& \text { wageu }=f\left(p^{f o i}, p^{m g s}, u r\right)
\end{aligned}
$$

\begin{tabular}{|c|c|c|}
\hline Average wage per worker & & \\
\hline eq. 217 & Long-run coefficients & \\
\hline Price index & $1 * * *$ & Method: OLS \\
\hline Unemployment rate & $-1.791 * * *$ & $\begin{array}{l}\text { Sample: } 1999 q 3-2019 q 2 \\
\text { Adj-R2: } 0.536\end{array}$ \\
\hline & Short-run coefficients & \\
\hline Price index & $-0.472 * *$ & \\
\hline Import prices & $0.064 *$ & \\
\hline 2003 dummy & 0.027 & \\
\hline 2005 dummy & 0.036 & \\
\hline
\end{tabular}

\section{Prices, Interest Rates, and Rates of Return}

The consumption deflator ( $p^{\text {cons }}$, eq. 218) is linked to our main price index through an ECM mechanism with a long-run elasticity of unity. We included a dummy for 2009Q1, which is found to be statistically significant.

$$
p^{\text {cons }}=f\left(p^{\text {foi }} ; \text { pmgs } ; \text { dum } 2009 q 1\right)
$$

\begin{tabular}{llll}
\hline \hline \multicolumn{1}{l}{ Consumption deflator } & & \\
\cline { 1 - 1 } eq. 218 & & Short-run coefficients & \\
& & & Method: OLS \\
Inflation rate & $0.828^{* * *}$ & Sample: 1996q2-2019q2 \\
Import prices & $0.047^{* * *}$ & Adj-R2: 0.814 \\
2009 dummy & $-0.008^{* * *}$ &
\end{tabular}

${ }^{25}$ The elasticity of wages to prices was larger than one, but since a test did not reject the hypothesis of a unit elasticity, we imposed this restriction. 
We next have a number of equations describing the interest rate, implicit interest rates, and rates of return for our assets. These will be used to link our variables to the main rates and variables, in order to give a systemwide dynamic. Of course, most of these specifications may well be improved, but it is not the purpose of this work to come out with the "best" econometric outcomes, but rather to capture the major interrelations among our sectors and overall financial dynamics.

The interest rate on deposits ( $r^{\text {deps }}$, eq. 219) is estimated with an ECM depending, in the long run, on the interest rate on ECB refinancing, the interest rate on loans on the interbank market with a maturity of three months (EURIBOR3), and the interest rate on government bonds, normalized to reduce multicollinearity among regressors. Heteroskedastic residuals are taken care of with the Huber-WhiteHinkley method. Diagnostics shows that autocorrelation is rejected, but residuals display nonnormality. Estimation output is reported below. It is worth noting that we kept track of the 2008-9 downturn without resorting to dummies. ${ }^{26}$

Next, we have the interest rates on our three different types of bank loans to domestic productive sectors, i.e., for mortgages, consumer credit, and loans to firms. We begin with the interest rate on mortgage credit (eq. 220), which depends on the same determinants of the rate on deposits plus the spread between Italian and German ten-year Treasuries. The same approach is used for the interest rate on consumer credit and interest rate on loans to nonfinancial firms (eqs. 221 and 222).

$$
r^{\text {deps }}=f\left(r^{a d v} ; E U R I B O R 3-r^{a d v} ; r^{b}-E U R I B O R 3\right)
$$

\begin{tabular}{|c|c|c|}
\hline \multicolumn{3}{|l|}{ Interest rate on deposits } \\
\hline eq. 219 & Long-run coefficients & \\
\hline$r^{a d v}$ & $0.648^{* * *}$ & Method: OLS \\
\hline$E U R I B O R 3-r^{a d v}$ & 1.145 & Sample: $1999 q 3-2019 q 2$ \\
\hline$r^{b}-E U R I B O R 3$ & $0.595 * * *$ & Adj-R2: 0.645 \\
\hline$r^{a d v}$ & $\begin{array}{l}\text { Short-run coefficients } \\
0.663^{* * *}\end{array}$ & \\
\hline
\end{tabular}

\footnotetext{
${ }^{26}$ In this regard, adding a dummy for 2011Q4 would improve the $R^{2}$ up to 74 percent. However, our strategy will be to not resort to dummies as long as we can keep track of the major dynamics without them.
} 


$$
r^{b l m o}=f\left(r^{a d v} ; E U R I B O R 3-r^{a d v} ; S P R E A D\right)
$$

\begin{tabular}{|c|c|c|}
\hline Interest rate on mortgages & & \\
\hline eq. 220 & Long-run coefficients & \\
\hline$r^{a d v}$ & $1.050 * * *$ & Method: OLS \\
\hline EURIBOR $3-r^{a d v}$ & $1.579 * * *$ & Sample: $1999 q 2-2019 q 2$ \\
\hline SPREAD & $0.316^{*}$ & Adj-R2: 0.939 \\
\hline & Short-run coefficients & \\
\hline$r^{a d v}$ & $0.549 * * *$ & \\
\hline EURIBOR $3-r^{a d v}$ & $0.594 * * *$ & \\
\hline
\end{tabular}

$$
r^{b l c c}=f\left(r^{a d v}\right)
$$

\begin{tabular}{|c|c|c|c|}
\hline \multicolumn{2}{|c|}{ Interest rate on consumer credit } & \multirow{5}{*}{\multicolumn{2}{|c|}{$\begin{array}{l}\text { Method: OLS } \\
\text { Sample: } 1999 q 2-2019 q 2 \\
\text { Adj-R2: } 0.906\end{array}$}} \\
\hline eq. 221 & Long-run coefficients & & \\
\hline$r^{a d v}$ & $1.00 * *$ & & \\
\hline & Short-run coefficients & & \\
\hline$r^{a d v}$ & $0.296 * * *$ & & \\
\hline \multicolumn{2}{|c|}{$r^{b l f i r m s}=f\left(r^{a d v} ; E U R I B O R 3-r^{a d v} ; S P R E A D\right)$} & & 222 \\
\hline \multicolumn{2}{|c|}{ Interest rate on loans to firms } & \multirow{7}{*}{$\begin{array}{l}\text { Method: OLS } \\
\text { Sample: } 1999 \mathrm{q} 2-2019 \mathrm{q} 2 \\
\text { Adj-R2: } 0.863\end{array}$} & \\
\hline eq. 222 & Long-run coefficients & & \\
\hline$r^{a d v}$ & $0.961 * * *$ & & \\
\hline SPREAD & $0.621 * * *$ & & \\
\hline & Short-run coefficients & & \\
\hline$r^{a d v}$ & $0.781 * * *$ & & \\
\hline EURIBOR3 $-r^{a d v}$ & $0.799 * * *$ & & \\
\hline
\end{tabular}

The interest rate on government bonds is determined by an autoregressive process, which links our implicit rate to the official one (eq. 223). We now have three more (implicit) interest rates to estimate: one for foreign issued liabilities and two for FDIs. We start with the changes in the (implicit) rate on foreign liabilities (eq. 224), simply estimated as a function of its lagged level and that on the ten-year German Bund. For the two FDIs, recall that we have both FDI "incoming" and "outgoing," so that we need to estimate the (implicit) rates of returns for both. Starting from the former, the (current) return on equity (RoE) for incoming FDI (eq. 225) is estimated as function of its lagged level, the current level of the exchange rate against the US\$, and the share price index for the United States. Finally, the changes in the (implicit) RoE on outgoing FDI (eq. 226) is simply estimated against its lagged values, the lagged return on domestic shares $\left(r_{t-1}^{e}\right)$, and a dummy for 2005Q2. 
These equations simply link implicit rates to observed variables, so we omit reporting details of the estimates.

$$
\begin{aligned}
& r^{b i}=f\left(r^{b}\right) \\
& r^{f}=f\left(r^{b 10 d e}\right) \\
& r^{f d i i}=f\left(x r^{i t \_u s e} ; s p^{u s}\right) \\
& r^{f d i o}=f\left(r^{e}\right)
\end{aligned}
$$

\section{Prices of Financial Assets}

Here we report the equations describing asset prices. We decided to model only the prices for shares, banks' equities and shares, foreign liabilities and FDI, and government bonds, while leaving the others exogenous. This choice was led by the finding, first, that the dynamics of most of these prices are difficult to model and, second, that, as we said many times, the more behaviors one models, the "heavier" the model becomes in terms of both the number of equations and the amount of dynamic links simultaneously at work. Of course a more descriptive specification would imply better estimates for the single equations, but this does not directly translate into more realistic systemwide dynamics and, moreover, it may well make the analysis of the results trickier given the possible multiple contrasting behaviors.

The strategy, thus, is to track the major effects that interest rates, real flows, and other assets prices have on the prices of our financial assets. Estimation outputs are available on request.

The price of government bonds is estimated as a function of its lagged value and the current interest rate on bonds (eq. 227). The growth in the price of banks bonds (eq. 228) is estimated against its lagged level on the ratio between interest paid by banks relative to the existing stock and the lagged level of the price and that of domestic shares, while the price of banks' shares (eq. 229) is simply linked to the general price index for the Italian stock market $\left(s p^{i t}\right)$, allowing for a structural break in 2011Q1. We then have the price of shares issued by domestic NFCs (eq. 230). This price is linked to a price index for the US stock market and the discrepancy between the Italian and US stock market price indexes. Residual are strongly autocorrelated, but normality is not rejected. 


$$
\begin{aligned}
& p^{b i}=f\left(r^{b}\right) \\
& p^{b b}=f\left(\frac{I N T P_{f c}}{B B} ; p^{b} ; p^{e n}\right) \\
& p^{e b}=f\left(s p^{i t}\right) \\
& p^{e n}=f\left(s p^{u s} ; \frac{s p^{u s}}{s p^{i t}}\right)
\end{aligned}
$$

Finally, we have the last set of prices, i.e. those of foreign issued liabilities (eq. 231) and that of FDI. Starting from the former, this is estimated as a function of its lagged value and that of the exchange rate against the US\$, and on the current level of the interest rate on the ten-year Bund. The (changes in the rate of growth of) prices for FDI are simply estimated as a function of $p^{f}$ (eqs. 232 and 233).

$$
\begin{aligned}
& p^{f}=f\left(x r^{\text {it_use }} ; r^{\text {b10de }}\right) \\
& p^{f d i i}=f\left(p^{\wedge} f\right) \\
& p^{f d i o}=f\left(p^{\wedge} f\right)
\end{aligned}
$$

\section{MODEL PROPERTIES}

\section{Validation against Historical Data}

In this section, we will show how the model performs in replicating historical data. We will only look at the most important variables, show some of the problems that emerge, and discuss how these may be resolved.

Starting with GDP, figure 4 displays the evolution of real GDP, in volumes and annual growth rates, showing that our estimate satisfactorily replicates historical data. The single components of GDP, in nominal values, ${ }^{27}$ are displayed in figure 5 . We overestimate consumption and investment for the period 2013-16 - thus leading to a higher GDP growth rate in the baseline for the relative period-and accurately track the dynamics of the other components of demand, with all trends clearly captured by the model.

\footnotetext{
${ }^{27}$ We display here variables at current prices instead of constant prices so that the discrepancy is due to both the error in tracking the variable at constant prices and to the error in simulating prices.
} 
Figure 4. Italy: Real GDP

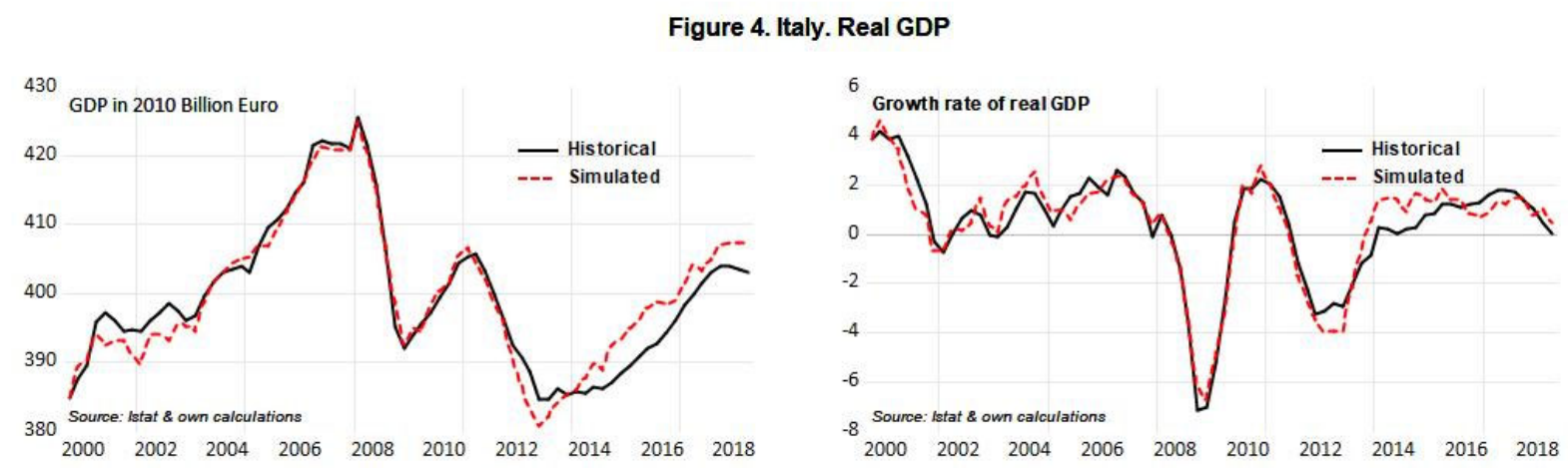

Model performance is not as satisfactory for aggregate financial balances, i.e., the net

lending/borrowing position of the institutional sectors. ${ }^{28} \mathrm{We}$ closely track the government balance (except for the period 2012-16) and only the overall dynamics with respect to other sectors. In particular, we underestimate net lending for the household and NFC sectors in the last part of the sample and overestimate it for financial firms during the same period. This may be due to accumulation of errors in previous lines of the transaction matrix that accumulate into net lending. In future research, the simulation error can be reduced with better econometric estimates.

With respect to the labor market, the unemployment rate, productivity level, and nominal wages are tracked satisfactorily.

${ }^{28}$ Additional details are available from the authors upon request. 
Figure 5. Italy: Components of GDP (in billion euro)

Figure 5. Italy. Components of GDP. Billion Euro.
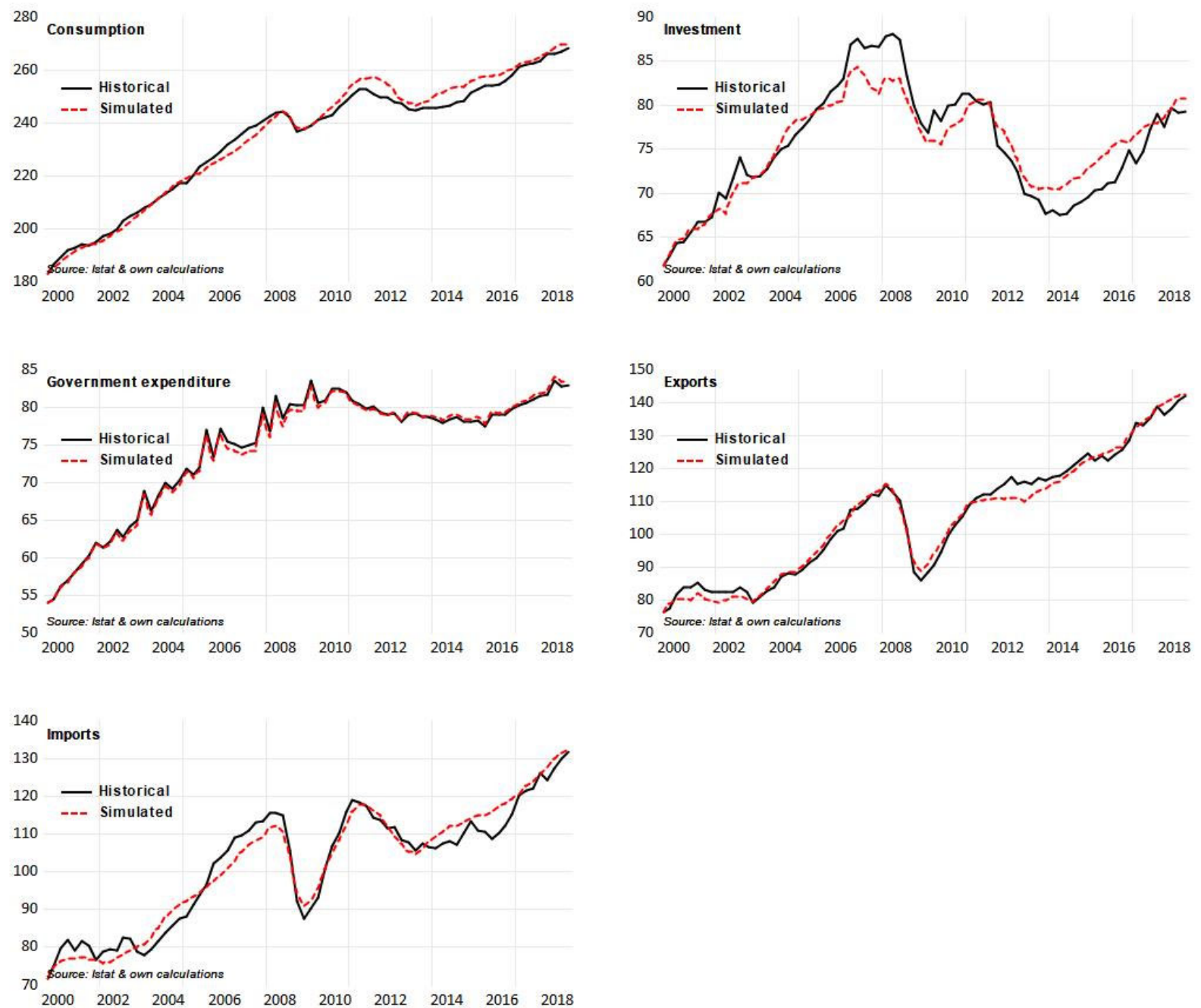

The model's ability to track financial stocks of assets and liabilities depends on whether the relevant estimated equations refer to stocks or flows. In the latter case, a statistical discrepancy between the fitted value and the actual value arising, say, from an outlier, will imply a shift in the level of the stock that may not revert to its historical level even if no large discrepancies appear in the remainder of the sample. This is the case for our simulation of loans to firms, for instance. ${ }^{29}$ Overall, the model replicates the dynamics of financial flows and those of most other stocks reasonably well.

\footnotetext{
${ }^{29}$ Deviations of simulated variables from their actual values has no impact when the model is used for simulation purposes, since such discrepancies are included automatically as additional exogenous variables, so that the baseline simulation replicates the data exactly.
} 
Our price indicators - which include the deflators for all components of GDP — as well as our interest rates are all tracked in a satisfactory way in our in-sample simulation.

\section{CONCLUSIONS}

In this paper we have presented a new quarterly model for the Italian economy that consistently integrates real and financial markets following the empirical methodology pioneered by Wynne Godley known as "stock-flow consistent approach."

However, Godley's empirical models are traditionally been much simpler, possibly for two reasons: the first is that, in the tradition of the "New Cambridge" approach, he was mainly interested in modeling the interrelation between the financial balance of the private sector as a whole and the financial balances of the public and foreign sectors. The other reason, connected to the first one, is that he often focused on countries with a large foreign deficit, which implies a leakage of aggregate demand that should be countered by an expansionary stance in the public sector, or else implies that aggregate demand can be sustained by the private sector only through increased borrowing from the other sectors, which will prove unsustainable in the long term.

The model presented here is an attempt to merge the SFC methodology for jointly tracking the real and financial sides of the economy to the methodology that was adopted for structural models by central banks around the world before the counterrevolution of rational expectations. Nowadays, as we have discussed in the introductory section, these structural models have evolved, incorporating microfoundations and rational expectations, which implies that monetary and financial markets can be treated separately. Given the failure of such models in projecting the dynamics that brought the Great Recession, we hope that the methodology suggested here can represent a starting point for a more robust alternative in structural modeling.

In our contribution (in particular in the appendix) we also show that the accounting structure of a detailed stock-flow model could — possibly should — be used by institutions producing financial and nonfinancial statistics for the institutional sectors to improve the quality of the data, which are currently affected by large discrepancies in measuring sectoral balances. 
As the number of researchers interested in the construction of empirical SFC models is growing, in this paper we have tried to show what type of practical problems arise and how they can be addressed using a pragmatic approach.

The strength of the model presented here is in the accounting consistency of all variables involved, as well as in the flexibility to handle changes in regimes, like those generated by the adoption of QE programs from the ECB. The weaknesses to be overcome are related to the still-unsatisfactory treatment of portfolio management, since the Tobinesque approach from which we started was apparently not coherent with the dynamics of the different assets' rates of return. This will need to be addressed in future research.

Is it necessary to reach this level of complexity when building an empirical SFC model for a whole country? We plan to address this issue by comparing the properties of the current model with those of a simpler model. Intuitively, the structure of a model like the one we presented here needs a team for the regular updates of the databases, revision of the estimates, and overall model development, which, as mentioned, is a task that can be handled by institutions that regularly produce policy analysis, but not by a single independent researcher.

To conclude, we wish to note that the analysis of SFC models is usually completed by developing a medium-term out-of-sample projection to evaluate the model's multipliers and evaluate the model's response to the most important policy shocks. We performed this analysis in previous months with useful results, but given the current major shock affecting the Italian economy from the lockdown imposed to address the COVID-19 epidemic, for which no macroeconomic data are yet available, we prefer to defer a description of policy experiments with this model to future research. 


\section{REFERENCES}

Angelini, E., A. D'Agostino, and P. McAdam. 2006. "The Italian Block of the ESCB Multi-Country Model.” European Central Bank Working Paper No. 660. Frankfurt: European Central Bank.

Bacchini, F., M. E. Bontempi, C. Brandimarte, R. Golinelli, C. Jona-Lasinio, and C. Pappalardo. 2013a. "The Macroeconometric Models for Italy (MeMo-It): Policy Evaluation and Future Challenges." Rivista Italiana Di Economia, Demografia e Statistica LXVII (2): 171-79.

Bacchini, F., C. Brandimarte, P. Crivelli, R. de Santis, M. Fioramanti, A. Girardi, R. Golinelli, et al. 2013b. "Building the Core of the Istat System of Models for Forecasting the Italian Economy: MeMo-It." Rivista Di Statistica Ufficiale 1.

Bagnai, A. and C. A. Mongeau Ospina. 2014. "The a/Simmetrie Annual Macroeconometric Model of the Italian Economy: Structure and Properties.” A/ Working Papers No. 2014/15. Rome: a/simmetrie.

Bezemer, D. J. 2010. "Understanding Financial Crisis through Accounting Models.” Accounting, Organizations and Society 35 (7): 678-88.

Brainard, W. C., and J. Tobin. 1968. "Pitfalls in Financial Model Building." American Economic Review 58 (2): 99-122.

Bulligan, G., F. Busetti, M. Caivano, P. Cova, D. Fantino, A. Locarno, and M. L. Rodano. 2017. "The Bank of Italy Econometric Model: An Update of the Main Equations and Model Elasticities." Banca d'Italia, Temi Di Discussione No.1130. Rome: Bank of Italy.

Busetti, F., A. Locarno, and L. Monteforte. 2005. “The Bank of Italy's Quarterly Model.” In G. Fagan and J. Morgan (eds.), Econometric Models of the Euro-Area Central Banks. Cheltenham, UK: Edward Elgar.

Cannari, L., G. D’Alessio, and G. Vecchi. 2016. "I Prezzi Delle Abitazioni in Italia, 1927-2012 (House Prices in Italy, 1927-2012).” Banca d'Italia Questioni Di Economia e Finanza No. 333. Rome: Bank of Italy.

Cicinelli, C., A. Cossio, F. Nucci, O. Ricchi, and C. Tegami. 2008. "The Italian Treasury Econometric Model (ITEM)." Ministry of Economy and Finance, Department of the Treasury Working Paper No. 1. Rome: Department of the Treasury.

De Bonis, R., and A. Gigliobianco. 2012. "The Origins of Financial Accounts in the United States and Italy: Copeland, Baffi and the Institutions." In R. De Bonis and A. F. Pozzolo (eds.), The Financial Systems of Industrial Countries. Berlin: Springer.

European Central Bank. 2017. "Base Money, Broad Money and the APP.” Economic Bulletin 6.

European Commission, International Monetary Fund, Organisation for Economic Co-operation and Development, United Nations, and World Bank. 2009. "System of National Accounts 2008." 
Fair, R. C. 2012. “Has Macro Progressed?” Journal of Macroeconomics 34: 2-12.

Galli, G., D. Terlizzese, and I. Visco. 1989. "Un Modello Trimestrale per La Previsione e La Politica Economica: Le Proprietà Di Breve e Di Lungo Periodo Del Modello Della Banca d'Italia." Politica Economica : Rivista Di Studi e Ricerche per La Politica Economica 5 (1): 3-51.

Godley, W. 1999. "Seven Unsustainable Processes.” Strategic Analysis. Annandale-on-Hudson, NY: Levy Economics Institute of Bard College. January

Godley, W., and M. Lavoie. 2007. Monetary Economics: An Integrated Approach to Credit, Money, Income, Production and Wealth. Cheltenham, UK: Palgrave Macmillan.

Gola, C., M. Burroni, F. Columba, A. Ilari, G. Nuzzo, and O. Panzarino. 2017. "Shadow Banking out of the Shadows: Non-Bank Intermediation and the Italian Regulatory Framework." Banca d'Italia Questioni Di Economia e Finanza No. 372. Rome: Bank of Italy.

Haavelmo, T. 2015. "Structural Models and Econometrics." Econometric Theory 31 (1): 85-92.

Hendry, D. F., and J. Muellbauer. 2018. "The Future of Macroeconomics: Macro Theory and Models at the Bank of England." Oxford Review of Economic Policy 34 (2): 287-328.

International Monetary Fund. 2009. "Balance of Payments and International Investment Position Manual, Sixth Edition." Washington DC: International Monetary Fund.

Keynes, J. M. 1936. The General Theory of Employment, Interest and Money. London, UK: MacMillan.

Lavoie, M. 2014. Post-Keynesian Economics: New Foundations. Cheltenham, UK: Edward Elgar.

Lavoie, M., and G. Zezza. 2011. The Stock-Flow Consistent Approach: Selected Writings of Wynne Godley. Basingstoke, UK: Springer.

McLeay, M., R. Amar, and R. Thomas. 2014. "Money Creation in the Modern Economy.” Bank of England's Monetary Analysis Directorate, Quarterly Bulletin Q1. London: Bank of England.

Muellbauer, J. 2016. "Macroeconomics and Consumption." University of Oxford, Department of Economics Discussion Paper No. 811.

Papadimitriou, D. B., M. Nikiforos, and G. Zezza. 2013. "A Levy Institute Model for Greece.” Technical Report. Annandale-on-Hudson, NY: Levy Economics Institute of Bard College.

Pappalardo, C., C. Rapacciuolo, and A. Ruocco. 2007. "Il Nuovo Modello Econometrico Trimestrale Del CSC per l'economia Italiana." Centro Studi Confindustria Working Paper No. 58. Rome: Centro Studi Confindustria.

Shaikh, Anwar. 2016. Capitalism: Competition, Conflict, Crises. NY: Oxford University Press. 
Stockhammer, E. 2008. "Is the NAIRU Theory a Monetarist, New-Keynesian, Post-Keynesian or Marxist Theory?” Metroeconomica 59 (3): 479-510.

Stockhammer, E., A. Guschanski, and K. Kohler. 2014. "Unemployment, Capital Accumulation and Labour Market Institutions in the Great Recession." Post Keynesian Economics Study Group Working Paper No. 1406. London: Post Keynesian Economics Society.

Tobin, J. 1969. “A General Equilibrium Approach to Monetary Analysis.” Journal of Money, Credit and Banking 1 (1): 15-29.

Visco, I., and G. Bodo. 1986. “Modello Trimestrale Dell Economia Italiana.” Banca d'Italia, Temi Di Discussione No. 80. Rome: Bank of Italy.

Welfe, W. 2013. Macroeconometric Models: Advanced Studies in Theoretical and Applied Econometrics, Vol. 47. Basingstoke, UK: Springer.

Zezza, F. 2018. "Stock-Flow Consistent Macroeconomic Models: Theory, Practice and Applications." PhD Thesis, University of Siena. Available at: http://phdeconomics.wp.unisi.it/wpcontent/uploads/sites/18/2019/01/Zezza2018_PhDEconomics_tesi-finale.pdf.

Zezza, G., and F. Zezza. 2019. "On the design of empirical stock-flow consistent models.” European Journal of Economics and Economic Policies: Intervention 16 (1): 134-58. 


\section{APPENDIX 1: FROM THE DATA TO THE MODEL}

\section{A1. Structural Models and Macroeconomic Accounts}

A "structural" model is such because it integrates a good deal of theory while remaining attached to the realism of the "environment" under analysis. ${ }^{30}$ The first step in model construction is thus to inspect the data to first get a first bird's eye view of the system under analysis. In theoretical models, the researcher has far more liberty in the decisions made about the number of sectors and assets to include, as well as on the closures and the behavioral specifications - all choices that may lead to a wide array of different models suited for the question at hand. When building an empirical model, in contrast, the first constraint everyone faces is related to the availability and structure of the appropriate data, from which all other decisions will follow.

In order to build a model that respects the theoretical requirements of the SFC approach, the core of the statistics must be the Nonfinancial Accounts of Institutional Sectors (NFA), published by Italy's national statistics institute (ISTAT) and available at quarterly frequency from 1999 to the present, and the Financial Accounts (FAIS), published by the Bank of Italy (BoI) and available at quarterly frequency from 1995 to the present.

\section{Figure A1. Italy: Household Net Lending}

Figure A1. Italy. Household net lending

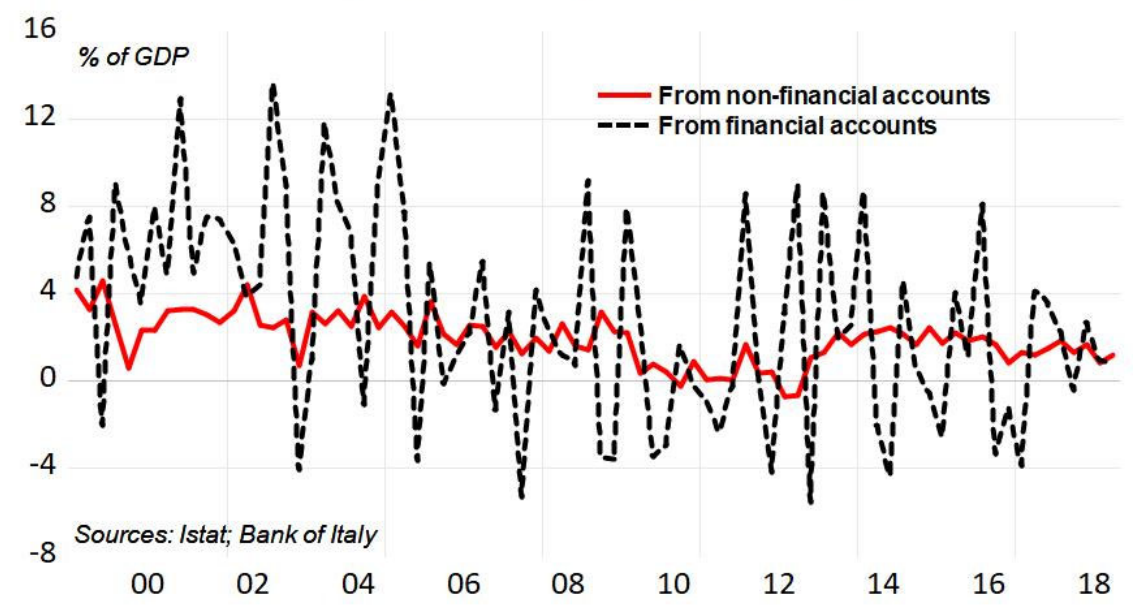

${ }^{30}$ See Haavelmo (2015). 
When using these data sources, five main problems arise.

- The first is that the NFA and FAIS are not necessarily consistent with each other. The NFA detail the sources of income for each sector and the expenditure on the current and capital accounts, ultimately determining saving and net lending. The FAIS provide details on how net lending can be broken down into changes in financial assets and liabilities. However, since the two sets of statistics come from different data sources - with the former being based on surveys on income and expenditure and the latter on balance sheet statistics and other sources from the financial sector- the measures of net lending for each sector do not necessarily match and, in fact, usually they don't, as displayed in figure A1.

To achieve consistency between the two data sources for modeling purposes, two strategies may be adopted. One could: (a) assume that financial data are measured more accurately than income and expenditure data and add the discrepancy to one of the determinants of saving for each sector (income or expenditure), or (b) one could treat the discrepancies as unexplained exogenous variables. The former strategy would make model simulations for consumption, income, or saving systematically different from data published in the national accounts, so the latter strategy is preferred. This strategy, however, implies that such exogenously given discrepancies be projected into the future for model simulations, increasing the degree of arbitrariness of model projections.

- The second problem in the Italian statistics for sectoral accounts is that they are not seasonally adjusted and, when adjusted with the X12 procedure, some aggregates do not exactly match the same concept published in the (seasonally adjusted) national accounts. This discrepancy is not large (for GDP it is between -0.8 percent and +0.8 percent) but will nonetheless imply additional exogenous variables to take the discrepancies into account, as well as introducing further discrepancies in model accounting. As an example, while the sum of interest paid out in the whole economy (including the RoW) is equal to the sum of interest income received (in the original, nonseasonally adjusted data), when each flow is seasonally adjusted, the accounting identity will register a discrepancy. 
- The third problem that needs to be addressed is that the NFA do not provide who-to-whom details for several flows, including:

○ direct taxes (some of which are paid to foreign institutions)

$\circ$ interest and dividends paid/received

○ social benefits other than "government individual consumption" expenditures

$\bigcirc$ other transfers on the current account

○ transfers on the capital account

To address this problem, three solutions are at hand.

- The first is to assume, given the trends in the data, how to allocate these payments. However, this increases the arbitrariness of the model and must be grounded in data exploration.

- The second is to resort to additional data sources that provide more details, namely:

- balance of payments statistics

- other financial statistics on holders of public debt

- other financial statistics providing details of the balance sheets of financial institutions

- Finally, if both the previous solutions are inapplicable, one may add an additional "pool" column to the transactions and balance sheet matrices. In this case, all sectors will receive/pay from/to the pool.

- The fourth problem is that if the model wants to address monetary policy, the central bank should be explicitly represented. This is the case for the FAIS, which provides details on the BoI's assets and liabilities, but not for the NFA. Using data on the BoI's balance sheet, we can separate the central bank's income flows and expenditure flows from income and payments of other monetary financial institutions (MFI). Since the adoption of the euro, the BoI has become part of the European System of Central Banks (ESCB), while the ECB is the (foreign) institution actively running monetary policy. To model financial transactions between domestic institutions and the ECB, we have to identify how and where such transactions are registered in financial accounts, balance of payment statistics, and other financial statistics that are available. 
- The fifth (and final!) problem is that Italian statistics are available only for a relatively short period of time at quarterly frequency, since the strategy adopted by ISTAT, contrary to other national statistical institutes, is not to revise statistical information backwards when a change in methodology is adopted, and the additional information to revise the data backwards are not available. Model development would benefit from the ability to compare data related to the period of flexible exchange rates (which started in 1971) to the period of managed exchange rates, to the common currency. However, we defer to future research the backwards expansion of the model, which requires appropriate procedures to infer quarterly data from available annual data, and estimation for variables of interest for which no information is available.

\section{A1.1. Level of Detail}

Available data from the NFA allow us to decompose the economy into five institutional sectors: households and nonprofit institutions serving households, NFCs, financial corporations (FCs), the public sector, and the RoW. Table A1 displays the NFA as of 2018.

\section{Table A1. Italy: Nonfinancial Accounts of Institutional Sectors, 2018 (million euro)}

\begin{tabular}{|c|c|c|c|c|c|c|}
\hline & Total economy & NFC & FC & GVT & HH & ROW \\
\hline \multicolumn{7}{|l|}{ Production account } \\
\hline Resources & $3,551,115$ & $2,315,182$ & 127,895 & 331,379 & 594,594 & 511,166 \\
\hline - Production & $3,369,051$ & $2,315,182$ & 127,895 & 331,379 & 594,594 & 0 \\
\hline - Imports of goods and services & 0 & 0 & 0 & 0 & 0 & 511,166 \\
\hline -- Imports of goods & 0 & 0 & 0 & 0 & 0 & 404,006 \\
\hline -- Imports of services & 0 & 0 & 0 & 0 & 0 & 107,160 \\
\hline $\begin{array}{l}\text { - Taxes net of contributions to } \\
\text { production }\end{array}$ & 182,064 & 0 & 0 & 0 & 0 & 0 \\
\hline Uses & $3,551,115$ & $2,315,182$ & 127,895 & 331,379 & 594,594 & 511,166 \\
\hline Intermediate consumption & $1,785,693$ & $1,491,649$ & 60,716 & 100,249 & 133,080 & 0 \\
\hline - Exports of goods and services & 0 & 0 & 0 & 0 & 0 & 555,286 \\
\hline -- Exports of goods & 0 & 0 & 0 & 0 & 0 & 451,298 \\
\hline -- Exports of services & 0 & 0 & 0 & 0 & 0 & 103,988 \\
\hline (=) $G D P$ & $1,765,421$ & 823,534 & 67,180 & 231,130 & 461,514 & 0 \\
\hline - Amortization & 308,789 & 165,407 & 4,312 & 48,616 & 90,453 & 0 \\
\hline - NDP & $1,456,633$ & 658,126 & 62,867 & 182,514 & 371,061 & 0 \\
\hline Net exports & 0 & 0 & 0 & 0 & 0 & $-44,120$ \\
\hline
\end{tabular}


Account of the generation of primary income

Resources

- GDP

- Contributions

Uses

- Wages

-- Gross wages

-- Contributions

- Taxes on imports and production

(=) Gross operating surplus and mixed income

Account of the distribution of primary income

Resources

- Gross operating surplus and mixed income

- Salaries

- Taxes on imports and production

- Capital Incomes

-- Interest

-- Distributed profits

--- Dividends

--- Retained earnings

-- Other distributed profits

-- Reinvest earnings from FDI

-- Transfers form producers' households

-- Other capital incomes

-- Rent

Uses

- Contributions

- Capital Incomes

-- Interest

-- Distributed profits

--- Dividends

--- Retained earnings

-- Other distributed profits

-- Reinvest earnings from FDI

-- Transfers form producers'

households

-- Other capital incomes

-- Rent

(=) Primary income

$\begin{array}{rrrrrr}1,796,560 & 828,471 & 67,188 & 231,130 & 465,700 & 0 \\ 1,765,421 & 823,534 & 67,180 & 231,130 & 461,514 & 0 \\ 31,139 & 4,938 & 8 & 0 & 4,185 & 0 \\ 1,796,561 & 828,471 & 67,188 & 231,130 & 465,700 & 6,450 \\ 708,925 & 457,055 & 32,512 & 172,362 & 46,996 & 6,450 \\ 518,578 & 335,450 & 22,475 & 120,431 & 40,221 & 5,461 \\ 190,347 & 121,605 & 10,036 & 51,931 & 6,775 & 989 \\ 256,675 & 23,483 & 4,014 & 10,152 & 14,954 & 0 \\ 830,961 & 347,933 & 30,662 & 48,616 & 403,749 & 0\end{array}$

\begin{tabular}{|c|c|c|c|c|c|}
\hline $2,352,389$ & 384,856 & 129,668 & 316,018 & $1,521,847$ & 59,710 \\
\hline 830,961 & 347,933 & 30,662 & 48,616 & 403,749 & 0 \\
\hline 713,468 & 0 & 0 & 0 & 713,468 & 1,907 \\
\hline 253,253 & 0 & 0 & 253,253 & 0 & 3,422 \\
\hline 554,708 & 36,923 & 99,006 & 14,149 & 404,630 & 54,381 \\
\hline 102,869 & 9,546 & 67,894 & 2,993 & 22,436 & 30,502 \\
\hline 162,219 & 18,251 & 15,814 & 6,821 & 121,334 & 12,863 \\
\hline 59,867 & 18,251 & 15,814 & 6,821 & 18,982 & 12,863 \\
\hline 60,081 & 0 & 0 & 0 & 60,081 & 0 \\
\hline 42,271 & 0 & 0 & 0 & 42,271 & 0 \\
\hline 12,175 & 8,046 & 4,129 & 0 & 0 & 10,577 \\
\hline 231,575 & 0 & 0 & 0 & 231,575 & 0 \\
\hline 40,319 & 910 & 11,170 & 0 & 28,240 & 439 \\
\hline 5,551 & 170 & 0 & 4,335 & 1,046 & 0 \\
\hline $2,352,389$ & 384,856 & 129,668 & 316,018 & $1,521,847$ & 72,458 \\
\hline 25,242 & 0 & 0 & 25,242 & 0 & 5,897 \\
\hline 542,528 & 170,641 & 69,477 & 64,776 & 237,634 & 66,561 \\
\hline 112,702 & 16,208 & 27,914 & 64,662 & 3,918 & 20,669 \\
\hline 159,232 & 140,752 & 18,480 & 0 & 0 & 15,850 \\
\hline 56,855 & 40,752 & 16,103 & 0 & 0 & 15,875 \\
\hline 60,106 & 58,130 & 1,976 & 0 & 0 & -25 \\
\hline 42,271 & 41,870 & 401 & 0 & 0 & 0 \\
\hline 10,577 & 10,385 & 192 & 0 & 0 & 12,175 \\
\hline 231,575 & 0 & 0 & 0 & 231,575 & 0 \\
\hline 22,891 & 0 & 22,891 & 0 & 0 & 17,867 \\
\hline 5,551 & 3,296 & 0 & 114 & 2,141 & 0 \\
\hline $1,784,620$ & 214,215 & 60,191 & 226,000 & $1,284,214$ & \\
\hline
\end{tabular}




\section{Account of the secondary distribution of incomes}

Resources

- Primary income

- Direct taxes

- Net social contributions

- Social contributions other transfers in nature

- Other current transfers

Uses

- Direct taxes

- Net social contributions

- Social contributions other transfers in nature

- Other current transfers

(=) Gross disposable income

Account of the redistribution of incomes in nature

Resources

- Gross disposable income

- Transfers in nature

Uses

- Transfers in nature

(=) Gross disposable income (corrected)

\section{Account of the uses of} disposable income

Resources

- Gross disposable income

- Variations in pension accounts

Uses

- Final consumption

-- Individual consumption

-- Collective consumption

- Variations in pension accounts

(=) Gross saving

Current account balance with

rest of the world

Account of the changes in net wealth due to savings and transfers

- Changes in liabilities and net wealth

-- Net saving

-- Transfers in capital account

- Changes in assets and net wealth

-- Transfers in capital account

-- Changes in net wealth due to savings and transfers in capital account

$\begin{array}{rrrrrr}2,780,464 & 241,550 & 100,128 & 728,774 & 1,710,013 & 34,437 \\ 1,784,620 & 214,215 & 60,191 & 226,000 & 1,284,214 & 0 \\ 248,834 & 0 & 0 & 248,834 & 0 & 1,357 \\ 270,409 & 19,623 & 14,001 & 234,941 & 1,844 & 989 \\ 379,359 & 0 & 0 & 0 & 379,359 & 1,823 \\ 97,242 & 7,712 & 25,936 & 18,999 & 44,596 & 30,268 \\ 2,780,464 & 241,550 & 100,128 & 728,774 & 1,710,013 & 17,027 \\ 247,630 & 27,869 & 5,789 & 1,088 & 212,884 & 2,561 \\ 270,811 & 0 & 0 & 0 & 270,811 & 587 \\ 376,675 & 16,668 & 9,919 & 348,794 & 1,294 & 4,507 \\ 118,138 & 13,477 & 27,653 & 27,069 & 49,939 & 9,372 \\ 1,767,210 & 183,537 & 56,766 & 351,823 & 1,175,084 & 0\end{array}$

$1,970,247$

183,537

56,766

351,823

$1,378,121$

351,823

$1,767,210$

183,537

203,037

$1,970,247$

203,037

183,537

56,766

$1,175,084$

203,037

$56,766 \quad 351,823 \quad 1,378,121$

9,501

193,536

$1,767,210$

183,537

56,766

158,287

$1,368,620$

351,823

$1,182,671$

$1,175,084$

7,586

$1,182,67$

$1,064,907$

$1,064,907$

193,536

142,241

2,955

4,082

16,046

549

117,214

366,525

180,581

52,684

0

0

$-45,908$

$\begin{array}{rrrrrr}82,996 & 31,507 & 49,915 & -28,729 & 30,303 & -44,643 \\ 57,736 & 15,174 & 48,372 & -32,570 & 26,761 & 0 \\ 25,259 & 16,333 & 1,544 & 3,841 & 3,542 & 1,265 \\ 82,996 & 31,507 & 49,915 & -28,729 & 30,303 & -44,643 \\ 24,431 & 827 & 315 & 20,397 & 2,893 & 2,093 \\ 58,564 & 30,680 & 49,601 & -49,126 & 27,410 & -46,736\end{array}$


Account of the acquisition of

nonfinancial assets

- Changes in liabilities and net

wealth

$\begin{array}{llllll}367,353 & 196,088 & 53,913 & -510 & 117,863 & -46,736\end{array}$

- Changes in assets

-- Investment

--- Gross fixed investment

367,353

196,088

320,618

182,342

53,913

313,325

175,113

6,455

$-510$

$117,863 \quad-46,736$

5,276

7,072

2,017

157

6,400

37,820

94,000

$37,602 \quad 94,210$

$-2,013$

1,803

1,483

$-169$

50

212

6

1,820

$-1,483$

--- Net acquisition of

assets

(=) Net Lending

45,253

13,914

$47,847 \quad-38,551$

$22,043 \quad-45,253$

Notes: NFC = Nonfinancial corporations; FC = Financial corporations; GVT = Public sector; HH = Households; ROW = Rest of the world. Million euro at current prices (2018)

Starting from the top, the first block records the RoW's production account, which registers exports, imports, and net indirect taxes paid domestically. The next block refers to the "generation of primary income": adding the contributions to production to the gross value-added of the various sectors and subtracting the costs of production (equal to wages and taxes on goods and services) yields the gross operating surplus (which includes mixed income).

The "attribution of primary income" block records the wages and indirect taxes received (by households and RoW for the former, and government and RoW for the latter), the subsidies paid and the capital incomes paid and received by the various institutional sectors (which are divided into interests, ${ }^{31}$ dividends, reinvested earnings from FDI, other incomes from investments, and rent from land) that, summed to gross profits, yields primary income. Next, we have the "distribution of secondary incomes": to primary income, we add and subtract direct taxes, benefits (which consist of net social contributions, other social transfers, and social transfers in-kind), and other current transfers, to get to disposable income. In the "uses of disposable incomes," from the post-tax income we add the variations in pensions entitlements and subtract consumption (collective and individual), and we get to saving.

\footnotetext{
${ }^{31}$ Note that interest income, as recorded in NFA, is net of services offered from the credit system for which there is no explicit charge (SIFIM) but are instead indirectly remunerated through the spread between active and passive rates. On the treatment of interest payments on deposits and loans in national accounting, see European Commission et al. (2009, sec. $6.163)$.
} 
The "variations in net wealth due to saving and transfers and capital account" records the transfers in capital account paid and received (consisting of taxes on capital account and other current transfers) that yields the variations in net wealth, while, finally, in the "net acquisition of non-financial assets," we find investments (in fixed capital and inventories) and other acquisitions of nonfinancial, nonproduced assets. What is left represents the net lending of the various sectors or, as Godley called it, the net acquisition of financial assets (NAFA). As it is clear from the table, the overall net lending position of the country matches the net borrowing position of the foreign sector. The equation that depicts the overall balance of private, public, and foreign sectors is known as the "fundamental identity" (Lavoie 2014). 
Table A2. Italy: Financial Balances, 2018 (in million euro)

\begin{tabular}{|c|c|c|c|c|c|c|c|c|c|c|}
\hline \multirow[t]{2}{*}{-> Sectors } & \multirow{2}{*}{$\mathrm{HH}$} & \multirow{2}{*}{$\mathrm{NFC}$} & \multicolumn{5}{|c|}{ Financial corporations } & \multirow{2}{*}{ GVT } & \multirow{2}{*}{ RoW } & \multirow{2}{*}{ Tot. } \\
\hline & & & $\mathrm{CB}$ & Banks & OFI & Fin Aux & Ins.\&Pens. & & & \\
\hline \multicolumn{11}{|l|}{ Financial Assets } \\
\hline Gold, monetary reserves & & & 95,097 & & & & & & 7,985 & 103,082 \\
\hline Banknotes and monetary deposits & 962,599 & 342,193 & 2,248 & 451,599 & 82,097 & 18,875 & 20,339 & 76,650 & 537,875 & $2,494,475$ \\
\hline Other deposits & 436,501 & 21,704 & 309,033 & 264,182 & 122,811 & 149,202 & 933 & 11,827 & 268,741 & $1,584,934$ \\
\hline Short-term assets & 898 & 203 & 7,583 & 26,579 & 9,165 & 3,669 & 8,241 & 58 & 72,755 & 129,151 \\
\hline Med.-/long-term assets & 279,968 & 58,817 & 532,219 & 798,358 & 168,415 & 44,249 & 575,169 & 41,389 & 844,453 & $3,343,037$ \\
\hline Derivatives & 1075 & 15,727 & 22 & 127,483 & 3,107 & 432 & 420 & & 94,810 & 243,076 \\
\hline Short-term loans & 11,714 & 46,334 & 907 & 432,709 & 30,107 & & 1,505 & & 117,923 & 641,199 \\
\hline Med.-/long-term loans & & 25,952 & 1,629 & $1,374,672$ & 276,853 & & 10,197 & 147101 & 166,585 & $2,002,989$ \\
\hline Shares & 904,524 & 626,348 & 9,891 & 159,716 & 205,184 & 37,871 & 112,795 & 158,606 & 533,235 & $2,748,170$ \\
\hline Shares of mutual funds & 453,079 & 18,236 & 1796 & 18,707 & 203,750 & 92,432 & 200,041 & 4,229 & 16,664 & $1,008,934$ \\
\hline Insurance technical reserves & $1,009,464$ & 11,228 & & 9,525 & & & 4,319 & 1,111 & 13,401 & $1,049,048$ \\
\hline Other accounts & 130,401 & 626,360 & & 13,566 & 3,718 & 104 & 4,784 & 123,326 & 101,476 & $1,003,735$ \\
\hline Total & $4,190,223$ & $1,793,102$ & 960,425 & $3,677,096$ & $1,105,207$ & 346,834 & 938,743 & 564,297 & $2,775,903$ & $16,351,830$ \\
\hline \multicolumn{11}{|l|}{ Financial Liabilities } \\
\hline Gold, monetary reserves & & & 7,985 & & & & & & 95,097 & 103,082 \\
\hline Banknotes and monetary deposits & & 46,153 & 821,933 & $1,247,978$ & & & & 168,048 & 210,364 & $2,494,476$ \\
\hline Other deposits & & & & $1,439,444$ & & & & 75,649 & 69,842 & $1,584,935$ \\
\hline Short-term assets & & 4,982 & & & 57 & & & 107,340 & 16,773 & 129,152 \\
\hline Med.-/long-term assets & & 145,321 & & 455,846 & 197,524 & & 16,478 & $1,985,122$ & 542,247 & $3,342,538$ \\
\hline Derivatives & 34 & 14,186 & 19 & 138,938 & 1,833 & 3,931 & 786 & 21,245 & 62,103 & 243,075 \\
\hline Short-term loans & 49,005 & 311,585 & & & 144,804 & 69,161 & 1779 & 11,540 & 53,324 & 641,198 \\
\hline Med.-/long-term loans & 672,013 & 771,513 & & 62,160 & 114,820 & 6,352 & 10,014 & 213,525 & 152,592 & $2,002,989$ \\
\hline Shares & & $1,695,816$ & 7,500 & 152,797 & 158,383 & 14,538 & 105,951 & & 613,185 & $2,748,170$ \\
\hline Shares of mutual funds & & & & 3,189 & 316,917 & & & & 688,829 & $1,008,935$ \\
\hline Insurance technical reserves & 37,701 & 106,462 & 7,298 & 4,417 & & & 843024 & 9,185 & 40,961 & $1,049,048$ \\
\hline Other accounts & 182,310 & 588,861 & & 2,602 & 1788 & 55 & 5,811 & 89,730 & 132,577 & $1,003,734$ \\
\hline Total & 941,063 & $3,684,879$ & 844,735 & $3,507,371$ & 936,126 & 94,037 & 983,843 & $2,681,384$ & $2,677,894$ & $16,351,332$ \\
\hline Net wealth & $3,249,160$ & $-1,891,777$ & 115,690 & 169,725 & 169,081 & 252,797 & $-45,100$ & $-2,117,087$ & 98,009 & 498 \\
\hline
\end{tabular}


FAIS, in turn, provides more disaggregated data for financial corporations, which are split between monetary financial institutions ("central bank" and "banks"), other financial institutions ("mutual funds" and "other"), financial auxiliaries, insurance companies, and pension funds (with separate balance sheets). Moreover, here the public sector is disaggregated into central government, local government, and the Italian Social Security system (INPS). Table A2 displays FAIS for the stocks in 2018. Starting from the top, we find "gold and monetary reserves," "banknotes and monetary deposits," and "other deposits" (which are held by MFI, other residents, and the RoW), "short-term assets" (issued by the government, other residents, and the RoW), "long-term assets" (issued by MFI, the government, other residents, and the RoW), "derivatives," "short-" and "long-term loans" (issued by MFI, the government, other residents, and the RoW), "shares" and "shares of mutual funds" (issued by domestic and foreign firms), "insurance technical reserves" (split into "life and pension fund," "insurances," and "others"), and, finally, "other accounts" (made of "commercial credit" and "others"). What is left represents the net wealth of the various sectors. ${ }^{32}$

It is relatively easy thus to obtain statistical information to separate the central bank from the rest of the financial sector, since sources of revenue and expenditure for the central are easy to identify. This allows one to build a model with six sectors, where each sector is relatively homogeneous, allowing for an easier identification of the determinants of the rules governing revenues, expenditures, and portfolio management for each sector. However, this level of detail implies that the number of accounting identities and "behavioral" equations to be specified increases exponentially.

\section{A1.2. Building the Balance Sheet}

In the current stage, the model's balance sheet has been built by simplifying the available information from the financial accounts of the institutional sectors, published by the BoI, through a careful analysis of stocks of assets and liabilities that play the most relevant role for the Italian economy, and is displayed in table A2.

The upper block of the balance sheet records "real assets." The stocks of nonfinancial assets have been reconstructed using some measures available at annual frequency, namely the stocks of nonfinancial

\footnotetext{
32 The net lending position of a sector, indeed, has corresponding equal changes in its balance sheet, mirrored by changes in the balance sheets of other sectors. Overall, the net lending position, as well as total financial wealth, are nil, so that all rows and columns in our matrices sum to zero.
} 
assets for each institutional sector, available from 2000 to 2018 with a sufficient breakdown (homes, other buildings, productive capital, consumer durables), and stocks and flows (gross capital formation and depreciation) measured at constant 2010 prices and substitution prices, available from 1995 to 2018 with the same breakdown. To obtain the quarterly series, we need to rely on the available flow measures for gross fixed capital formation, available from 1995 (1996 for fixed price measures) to the present.

We use the available data at quarterly frequency to obtain the stock of nonfinancial assets at the end of each quarter, given by: ${ }^{33}$

$$
K_{t}=K_{t-1}+G F C F_{t}-D E P_{t}
$$

Where all variables are measured at constant 2010 prices and $D E P_{t}$ is depreciation. We then obtain the estimate of stocks at market prices from (A1.2):

$$
K_{t}=p_{t}^{K} \cdot k_{t}
$$

where $p^{K}$ is an appropriate market price.

Statistics on the market price of productive capital are not available, so we will simply use the investment deflator. For housing, we evaluated the implicit price measure, which results from the stock reported in NFA, and the quarterly series published by ISTAT from 2010 onward. For the years before 2010 we interpolated the annual index constructed in Cannari, D'Alessio, and Vecchi (2016).

Finally, we need to allocate the stock of each nonfinancial asset to one of the institutional sectors. For 2015, the values and shares of nonfinancial assets are reported in table A3.

\footnotetext{
${ }^{33} \mathrm{We}$ interpolated the stock of capital by type of asset, using the share of gross fixed capital formation in each quarter to allocate the overall annual increase in the stock over quarters. This procedure assumes that, in each year, the ratio of capital consumption to gross fixed capital formation is constant (but changing from one year to the next).
} 
Table A3. Stocks of Nonfinancial Assets of Institutional Sectors, 2015

\begin{tabular}{|c|c|c|c|c|c|c|c|c|c|}
\hline & \multicolumn{2}{|c|}{ Households } & \multicolumn{2}{|c|}{ NFCs } & \multicolumn{2}{|c|}{ Fin. Corp. } & \multicolumn{2}{|c|}{ Government } & $\underline{\text { Tot. }}$ \\
\hline & $\mathrm{Bn}$ & $\%$ & $\mathrm{Bn}$ & $\%$ & $\mathrm{Bn}$ & $\%$ & $\mathrm{Bn}$ & $\%$ & $\mathrm{Bn}$ \\
\hline Housing & 5,345 & 92 & 383 & 7 & 10 & 0 & 90.7 & 2 & 5,829 \\
\hline Other buildings & 707 & 30 & 1,312 & 55 & 91 & 4 & 255 & 11 & 2,365 \\
\hline Productive capital & 77 & 11 & 539 & 78 & 4 & 1 & 74 & 11 & 694 \\
\hline Cultivated land & 219 & 89 & 18 & 7 & 0 & 0 & 10 & 4 & 247 \\
\hline Durables & 561 & 100 & & 0 & & 0 & & 0 & 561 \\
\hline Total & 6,909 & 71 & 2,252 & 23 & 105 & 1 & 430 & 4 & 9,696 \\
\hline
\end{tabular}

Although it is apparent that the household sector owns a considerable share of other buildings, since we will not try to model the supply side by institutional sector in this version of the model, we have decided to simplify the model's balance sheet by allocating the whole of housing to the household sector (net of the government share) and the whole of the privately owned "other buildings" and "productive capital" to NFCs.

Next, lines 6 to 8 of the model's balance sheet deal with central bank operations. The BoI is part of the ESCB and, although it acts as the domestic agent of the ECB, which is a supranational (foreign?) institution, it is part of domestic financial corporations. ${ }^{34}$

For the purposes of the model, it was useful to obtain additional information with respect to that provided in the FAIS. In the FAIS, the central bank's main liability is in the category "sight deposits with MFI," at 719 billion euro in 2017Q1. Information available from the BoI's balance sheet ${ }^{35}$ allows us to split this category into banknotes in circulation (179 billion euro), bank reserves ( 87 billion euro), and the Target 2 balance with the ECB (420 billion euro), reaching a reasonable who-to-whom representation.

On the asset side, apart from the refinancing operations for banks, we chose to focus on three major sets of assets: (1) gold and foreign reserves,${ }^{36}$ which are a liability of the (extra-euro) RoW and have

\footnotetext{
${ }^{34}$ For the statistical treatment of central banks in monetary unions, see European Commissions' System of National Accounts (SNA) (European Commission et al. 2009, 89) and the Balance of Payment Manual (International Monetary Fund 2009): "Typically, the Currency Union Central Bank (CUCB) maintains national offices in each member economy. This institutional unit, called 'the national agency,' acts as the central bank for that economy and must be treated for statistical purposes as an institutional unit that is separate from the headquarters of the CUCB."

${ }^{35} \mathrm{BoI}$ (December 10, 2019), Moneta e Banche: serie nazionali, tables 3.3a \& 3.3b.

${ }^{36}$ These are made up of assets and liabilities against extra-euro RoW and liabilities against the special drawing rights (SDR) system.
} 
been slowly increasing; (2) foreign liabilities held; and (3) government bonds held, which have been relatively stable up to 2011, and have risen spectacularly with the QE programs (in particular with the PSPP launched in March 2015), reaching more than 300 billion euro in 2017. As it is well-known, the BoI is purchasing such bonds on the secondary market, and indeed the increase in the stock of public bonds held in 2017Q1 is more than three times the increase in the total stock of bonds outstanding. As we shall see later, the increasing share of government bonds held by the BoI is matched by a similar decrease in the share of such bonds held by domestic financial corporations and foreign actors, while bonds held by households have remained relatively stable.

In the current stage of the model we have netted out the BoI's position with the ECB, subtracting the assets from the liabilities, and finally we have obtained a residual category for "other net financial assets," which was relatively large compared to total BoI assets up to 2005, but it is now almost negligible, at 3 percent of total assets in 2017Q1.

We can now turn to financial corporations. These play the crucial role of "fuel" of the system, providing credit for consumption and investment. Line 9 of the model's balance sheet records banks' deposits. Banks hold deposits of households, firms, the public sector, and the RoW ${ }^{37}$ (these are the sums of "banknotes and monetary deposits" and "other deposits"). Next, lines 10 to 12 records banks' loans. In the model, banks provide loans to households as consumer credit (BLCC) and as mortgage credit $(B L M O)$, and to firms as investment finance (BLFIRMS). As we said earlier, from the FAIS we have information on assets and liabilities issued by MFI and held by the various institutional sectors relative to short- and medium-to-long term loans. Thus, BLCC will be equal to the stock of short-term loans issued by MFI held by households, BLMO to the stock of long-term loans issued by MFI held by households, and BLFIRMS to the sum of the stocks of short- and long-term loans issued by MFI and held by NFCs. Next, in line 13, we find banks' debts. These are the stock of banks' liabilities of "longterm assets," which in the model are an asset held by households and the RoW only. To close with the banking sector, line 14 records bank-issued shares held by households only. We used this assumption for the sake of simplicity, but foreign capital in Italian banks' equities is relevant, and should be treated more properly.

\footnotetext{
${ }^{37}$ The rest of the deposits are held by the central bank, for the "other deposits" part (200 billion) and the banking sector ( 380 billion in "banknotes and monetary deposits" and 340 billion in "other deposits," which have been consolidated into FC). These are omitted from the model: 1) for the sake of simplicity, and 2) because only a small part of the "banknotes and monetary deposits" of banks is held abroad, and most of these deposits are inside the banking sector itself.
} 
Having closed the discussion of the financial corporate sector, we can now turn to the government. In the model, the public sector only holds deposits, domestic firm's shares, and a residual category of other net assets (ONFA), while it issues debt (line 15), which is in turn held by all other sectors.

From the FAIS, we have disaggregated data (as previously noted, for 13 sectors $^{38}$ ) relative to assets issued by the government. In particular, we have information on:

- Treasuries (certificati di credito del Tesoro, or CCT) from the central government;

- non-CCT from the central government;

- long-term assets from the local government; and

- short-term assets from the central government

We will use the stock on the asset side of the holding sectors and attribute it to the government, adding the usual discrepancy variable to make our measure match official data on public debt.

Next, line 16 records firms' issued shares. These, together with bank loans and retained earnings, constitute their other major source for investment finance. To make the best out of these data sources, some consolidations and simplifications are in order. As we said, the FAIS has information on both shares of firms (domestic, "listed" domestic, and foreign) and of mutual funds (domestic and foreign). To keep things simple, ease the analysis, and better appreciate the channels at work, we only focus on domestic firms' shares, which are assumed to be issued to households, financial corporations, and the government. Moreover, all FCs but banks and financial auxiliaries have been consolidated into the household sector. This is so because households usually use these as intermediaries to acquire financial instruments, resulting in the appearance of these assets on FCs' balance sheets.

It shall be noted, however, that several complications arise in the case of shares. First, it may well be possible that there is cross holding of shares between firms. Second, since we want to identify the FDI portion of shares, we only track the assets found on the balance sheets of the holding sectors and assign

${ }^{38}$ Recall that, for model purposes, all financial institutions with the exception of the central bank are added up to form the financial corporation sector (FC). Moreover, the public sector is made up of central and local governments and the INPS. 
it as a liability for NFCs. Of course, using this procedure we will somewhat underestimate the shares issued domestically.

Lines 17-19 record the foreign sector block of our model's balance sheet. As we said, we wanted to clearly identify FDI, both incoming and outgoing. In order to do this, we set FDI "outgoing” (FDIO) as the stock of foreign shares held by domestic firms while "incoming" FDI (FDII) are the stock of shares of domestic firms held by foreigners. Next, we find foreign-issued liabilities $(\mathrm{F})$, which are held by households, financial corporations, and the central bank. These consist of short- and long-term instruments plus the shares of mutual funds issued by the RoW.

Finally, line 20 is a residual asset category (other net financial assets [ONFA]) that we use to achieve accounting consistency as the difference between total assets minus total liabilities as they appear in the FAIS and all other assets/liabilities in the relative sector portfolio. Line 21 represents the sectoral net wealth.

It should be underlined, however, that we have made a number of simplifications. In the case of shares, holdings of public debt, and technical insurance reserves, for example, all FCs' balance sheets but those of banks and financial auxiliaries have been consolidated into the household sector. This is so because households' use of these nonbank financial institutions as intermediaries in the acquisition of financial instruments has been on the rise in recent times due to financialization processes, resulting in the appearance of these assets on FCs' balance sheets. These kinds of simplifications, however, heavily depend on the country under analysis. ${ }^{39}$ The assumption made here is indeed supported by empirical studies by ISTAT and the BoI, which discuss the recent increasing role of nonbank financial intermediaries in households' wealth management. ${ }^{40}$ In countries like the United States, for example, where pension funds play such an important role, it could be misleading not to model it separately.

\footnotetext{
${ }^{39}$ Zezza and Zezza (2019) argue that the structure of an empirical SFC model should start from a careful analysis of the specificity of a country's sectoral balance sheets by drawing on examples for Greece and Italy.

${ }^{40}$ See Gola et al. (2017).
} 


\section{APPENDIX 2: INTEGRATING OTHER DATA}

\section{A2.1. Capital Gains and Asset Prices}

For the $i-t h$ sector, we model the stock of net financial assets at market prices $(N F A)$ from the corresponding net flow:

$$
N F A_{i, t}=N F A_{i, t-1}+N E T L E N D F_{i, t}+N K G_{i, t}
$$

Where NETLENDF is the net lending, as published in the FAIS, and $N K G$ is net capital gains, measured as the residual from (A2.1). For the household sector, we also estimate the stock of net financial assets at historical prices $\left(N F A_{-} H P\right)$ by accumulating the relative net flow (i.e., ignoring capital gains, and therefore fluctuations due to changes in the market price of assets).

$$
N F A_{-} H P_{h h, t}=N F A_{-} H P_{h h, t-1}+N E T L E N D F_{h h, t}
$$

The rationale for determining $N F A_{-} H P$ is that, while consumers are likely to adjust expenditure with changes in their total net financial wealth, it is implausible that they adjust their expenditure, quarter by quarter, with changes, say, in the stock market price index. Secondly, there is a technical consideration. We need to recall that the goal is to build a fully empirical SFC model, where all structural (behavioral) equations will have to be estimated with the appropriate techniques. The series upon which these estimations would have to be performed, thus, need to be as "smooth" as possible if we want to achieve robust parameters and meaningful results. However, if we also want to model assets at historical prices, we will need additional identities and equations in the model, increasing its complexity.

Net capital gains should be due to changes in the market price of assets, but also to write-offs due to bankruptcy. In principle, and abstracting from write-offs of debt, if $e$ is one equity with a market value $p^{E}$, the market value of the stock of equities evolves following:

$$
E_{t} \cdot p_{t}=E_{t-1} \cdot p_{t}^{E}+f_{t} \cdot p_{t}^{E}
$$


where $f_{t}$ is the number of new equities issued during the period. Notice that the number of equities at the beginning of the period (i.e. $E_{t-1}$ ) must be valued at the current market price. Adding and subtracting $e_{t-1} \cdot p e_{t-1}$, we get:

$$
E_{t} \cdot p_{t}=E_{t-1} \cdot p_{t-1}^{E}+f_{t} \cdot p_{t}^{E}+\left(E_{t-1} \cdot p_{t}^{E}-E_{t-1} \cdot p_{t-1}^{E}\right)
$$

Multiplying and dividing by $p_{t-1}^{E}$ in the last bracket, and using $E_{t}=E_{t} \cdot p_{t}^{E}$, we get:

$$
E_{t}=E_{t-1}+F_{t}+\dot{p}_{t}^{E} \cdot E_{t}
$$

where $\dot{p}_{t}^{E}$ is the rate of change in $p^{E}$. Net capital gains, abstracting from write-offs, are equal to the rate of change in the market price of the asset, multiplied by the opening stock of assets. We have used equation (A2.5) to compute the rate of change in each asset, given the values of the stocks available from the balance sheets and the value of flows.

A problem emerges, in practice, when more than one sector is holding the stock $E$ as an asset. In principle, we could use equation (A2.5) for each sector, and assuming that each sector holds the same basket composing $E$, the rate of change in the market price should be the same, or at least similar, when computed from different sectors' data. If, however, each sector holds a different component of the total basket defining $E$, the market price of each respective basket will vary. The problem is even more severe when we allow for write-offs.

One way to address the issue and obtain consistent identities, would be to split equation (A2.5) for the different baskets for each sector and use different prices for each basket, with $p e$ the weighted average for all equities. However, since this procedure implies the proliferation of price variables for financial assets, which sometimes have unpredictable dynamics, we preferred to use a shortcut, which is to: (a) compute the market price of the aggregate stock, (b) compute net capital gains for each sector on the basis of the overall market price, and (c) compute a residual component. For each sector, thus, we have:

$E_{i, t}=E_{i, t-1}+F_{i, t}+\dot{p}_{t}^{E} \cdot E_{i, t}+N K G D_{i, t}$ 
where $N K G D$ is the discrepancy for the $i-t h$ sector arising from the different composition of the basket of the $i-t h$ sector against the total basket.

\section{A2.1.1. Net Capital Gains by Asset}

Next, we compute net capital gains for each asset of the model. Following the classification of financial assets in the balance sheet, we have the following.

Gold held at the central bank: The "real" stock of gold (GOLDQ) is estimated at $\mathrm{t}=1$ dividing the stock at market prices $(G O L D)$ by the market price of gold ( $\left.p^{\text {gold }}\right)$. The real stock is then accumulated over time using:

$$
G O L D Q_{t}=G O L D Q_{t-1}+\frac{V G O L D_{t}}{p_{t}^{g o l d}}
$$

where $V G O L D$ is the euro value of net flows in gold at the central bank. The accounting identity for the value of gold implies a discrepancy, NKGD_GOLD:

$$
G O L D_{t}=G O L D_{t-1}+V G O L D_{t}+p_{t}^{\text {gold }} \cdot G O L D_{t-1}+N K G D_{-} G O L D_{t}
$$

Monetary base and bank deposits: The stocks of monetary base and bank deposits obviously should not imply capital gains. However, comparing the change in the end-of-period stocks of deposits to the corresponding flow, there are discrepancies, which we compute as write-offs and treat as exogenous, according to:

$$
D E P S_{i, t}=D E P S_{i, t-1}+V D E P S_{i, t}-D E P S W O_{i, t}
$$

Consumer credit: The comparison of the changes in the stock of consumer credit to the corresponding flow suggests that the difference is due to write-offs of nonperforming loans, so that:

$$
B L C C_{t}=B L C C_{t-1}+V B L C C_{t}-B L C C W O_{t}
$$


Write-offs (BLCCWO) have been rapidly increasing since 2010. Again, we treat BLCCWO as exogenous, so that the write-offs will not play a role in model accounting. ${ }^{41}$

Mortgages: Long-term loans to households follow a similar pattern as consumer credit, i.e., computing the stock of such loans by accumulating the flows and comparing the result to the current value of loans shows that the latter is always below the former by an amount presumably due to write-offs. We therefore adopt a similar identity rather than trying to infer an implicit "market price" of mortgages:

$$
B L M O_{t}=B L M O_{t-1}+V B L M O_{t}-B L M O W O_{t}
$$

The determination of the change in the stock of mortgages (VBLMO) will be discussed later.

Loans to NFCs: Inspection of stocks and flows reveals similarities to consumer credit in that revaluation seems to be due to write-offs rather than changes in the market price of loans, so we use:

$$
\text { BLFIRMS }_{t}=\text { BLFIRMS }_{t-1}+\operatorname{VBLFIRMS}_{t}-\text { BLFIRMSWO }_{t}
$$

The net increase in loans to firms (VBLFIRMS) will be determined from the residual need for liquidity of the firms' sector, as discussed below.

Banks securities: We have assumed that banks' debts other than equities are held by households and the foreign sectors. Comparing the published measure at market prices to the stock of debt obtained by accumulating the flows, we notice that the former is always slightly higher than the latter, so the difference cannot be interpreted as debt write-off, even for recent periods when some Italian banks saw the market value of their securities collapse.

We therefore chose to model the stock revaluation as a change in the market price of the stock. One solution would be to compute the revaluation separately for assets held by households and for those held by the foreign sector, with the aggregate percentage change in price given by a weighted average of the two components. Namely:

${ }^{41}$ The write-offs so calculated are not large anyway. The stock of consumer credit, as used in the model, is rather modest in Italy, at 3 percent of GDP. The highest write-off we estimate was 0.3 percent of GDP, in 2017Q2. 


$$
\begin{aligned}
& B B_{h h, t}=B B_{h h, t-1}+V B B_{h h, t}+p_{h h, t}^{\dot{B B}} \cdot B B_{h h, t-1} \\
& B B_{\text {row }, t}=B B_{\text {row }, t-1}+V B B_{\text {row }, t}+p_{\text {row }, t}^{B \dot{B}} \cdot B B_{\text {row }, t-1} \\
& p_{t}^{\dot{B} B}=p_{h h, t}^{\dot{B B}} \cdot \frac{B B_{h h, t-1}}{B B_{t-1}}+p_{\text {row }, t}^{B \dot{B}} \cdot \frac{B B_{\text {row }, t-1}}{B B_{t-1}}
\end{aligned}
$$

However, the dynamics of the market prices for the two subcomponents is quite erratic and difficult to model, so we therefore preferred to estimate the market price from the aggregate stock, assuming that the two sectors hold the same basket of banks' debts, and compute the residual as a discrepancy, so that the identity becomes:

$$
\begin{aligned}
& B B_{h h, t}=B B_{h h, t-1}+V B B_{h h, t}+p_{h h, t}^{\dot{b b}} \cdot B B_{h h, t-1}+D I S C_{-} V B B_{h h, t} \\
& B B_{\text {row }, t}=B B_{\text {row }, t-1}+V B B_{\text {row }, t}+p_{\text {row }, t}^{B \dot{B}} \cdot B B_{\text {row }, t-1}+D I S C_{-} V B B_{\text {row }, t}
\end{aligned}
$$

implying that $D I S C_{-} V B B_{h h, t}+D I S C_{-} V B B_{\text {row }, t}=0$

Bank-issued shares: We have assumed that banks' equities are held only by domestic households, although this assumption should be relaxed in future releases, given the relevance of FDI in the financial sector. Our assumption simplifies the accounting and we abstract from write-offs for this asset, using simply:

$$
E B_{t}=E B_{t-1}+V E B_{t}+p_{t}^{\dot{E} B} \cdot E B_{t-1}
$$

In the model, we assume that the decision on the value of net new equities $(V E B)$ is made exogenously by banks, and that the households are always willing to purchase new equities when issued.

Government bonds: The treatment of government bonds will be similar to that of banks' debts, since the implicit market price that can be obtained from computing the revaluation account of sectors holding these bonds is not easy to establish. We therefore compute a single market price from the aggregate stock of bonds, as well as discrepancies for each sector, with discrepancies summing up to zero. 
For each sector $i$ we have:

$$
B_{i, t}=B_{i, t-1}+V B_{i, t}+\dot{p}_{t}^{B} \cdot B_{i, t-1}+D I S C_{-} V B_{i, t}
$$

where $p \dot{b}_{t}$ is computed from:

$$
B_{t}=B_{t-1}+V B_{t}+\dot{p_{t}^{B}} \cdot B_{t-1}
$$

The supply of new government bonds is determined by the government's financing needs, while the demand side will be modeled differently according to the sectors.

Firms' equities: The implicit market price of firms' equities that can be obtained by the revaluation account of sectors holding these assets (i.e., households, financial firms, and the government) shows that the dynamics for the financial sector are markedly different from the other two sectors. This is possibly the result of our simplifying assumption for computing the portfolio of the financial sector, and again suggests modeling the market price with the same method adopted for banks' debts and government bonds:

$$
E N_{i, t}=E N_{i, t-1}+V E N_{i, t}+p_{t}^{\dot{E} N} \cdot E N_{i, t-1}+D I S C_{-} V E N_{i, t}
$$

where $p_{t}^{\dot{E} N}$ is computed from:

$$
E N_{t}=E N_{t-1}+V E N_{t}+p_{t}^{\dot{E} N} \cdot E N_{t-1}
$$

The supply of new equities (VEN) is modeled as an autonomous decision of firms (the flow of equities has been negative, on average, since 2014), while the demand will be modeled differently according to the sectors. 
Foreign direct investment: "Incoming" and "outgoing" FDI are modeled as a relation between domestic nonfinancial firms and foreign firms, and we chose to ignore potential write-offs and use the stock-flow identity to compute an implicit market price for each of the two assets ${ }^{42}$ :

$$
\begin{aligned}
& F D I I_{t}=F D I I_{t-1}+V F D I I_{t}+p_{t}^{\dot{F D I I}} \cdot F D I I_{t-1} \\
& F D I O_{t}=F D I O_{t-1}+V F D I O_{t}+p_{t}^{F \dot{D} I O} \cdot F D I O_{t-1}
\end{aligned}
$$

Foreign liabilities: We assume that foreign liabilities are held by households, financial firms, and the central bank. When computing the implicit market price index from the stock-flow identity, the implicit market price for central bank holdings has very different dynamics from the other two, so we again resort to using a discrepancy and computing the market price of these assets from the aggregate stock:

$$
F_{i, t}=F_{i, t-1}+V F_{i, t}+\dot{p_{t}^{F}} \cdot F_{i, t-1}+D I S C_{-} V F_{i, t}
$$

where $p_{t}^{F}$ is computed from:

$$
F_{t}=F_{t-1}+V F_{t}+\dot{p_{t}^{F}} \cdot F_{t-1}
$$

\footnotetext{
${ }^{42} \mathrm{We}$ abstracted from exchange rate movements, which would have been incorporated in this FDI. The role of the exchange rate should be taken into account in further developments. However, if a large part of FDI is with other eurozone countries, the exchange rate should not be so relevant.
} 
Other net financial assets: Other net financial assets are treated exogenously. Net capital gains on these assets $\left(N K G_{-} O N F A\right)$ for each sector are obtained residually so that:

$$
O N F A_{i, t}=O N F A_{i, t-1}+V O N F A_{i, t}+N K G_{-} O N F A_{i, t}
$$

\section{A2.1.2. The Revaluation Account: Vertical Consistency}

We are now able to specify the component of net capital gains (including write-offs) for each sector:

$$
\begin{aligned}
& N K G_{h h, t}=p_{h h, t}^{\dot{B B}} \cdot B B_{h h, t-1}+p_{h h, t}^{\dot{E B}} \cdot E B_{h h, t-1}+p_{h h, t}^{\dot{B}} \cdot B_{h h, t-1}+p_{h h, t}^{\dot{E N}} \cdot E N_{h h, t-1}+p_{h h, t}^{\dot{F}} \cdot F_{h h, t-1}+ \\
& B L C C W O_{t}+B L M O W O_{t}+D I S C_{-} V B_{h h, t}+D I S C_{-} V E N_{h h, t}+D I S C_{-} V F_{h h, t}+N K G_{-} O N F A_{h h, t} \\
& N K G_{n f c, t}=p_{n f c, t}^{\dot{B}} \cdot B_{n f c, t-1}+p_{n f c, t}^{E \dot{N}} \cdot E N_{t-1}+p_{t}^{F \dot{D} I O} \cdot F D I O_{t-1}-p_{t}^{\dot{F D I I}} \cdot F D I I_{t-1}+B L F I R M S_{t}+ \\
& D I S C_{-} V B_{n f c, t}+N K G_{-} O N F A_{n f c, t} \\
& N K G_{c b, t}=p_{t}^{G \dot{O O L D}} \cdot G O L D_{t-1}+p_{c b, t}^{\dot{B}} \cdot B_{c b, t-1}+p_{c b, t}^{\dot{F}} \cdot F_{c b, t-1}+D I S C_{-} V B_{c b, t}+N K G_{-} O N F A_{c b, t}+ \\
& N K G_{-} G O L D_{t} \\
& N K G_{g v t, t}=p_{g v t, t}^{E \dot{E}} \cdot E N_{g v t, t-1}-p_{t}^{B} \cdot B_{t-1}+N K G_{-} O N F A_{g v t, t} \\
& N K G_{r o q, t}=-p_{t}^{G \dot{O O L D}} \cdot G O L D_{t-1}+p_{r o w, t}^{B \dot{B}} \cdot B B_{r o w, t-1}-p_{t}^{F \dot{D I O}} \cdot F D I O_{t-1}+p_{t}^{F D I I} \cdot F D I I_{t-1}-p_{t}^{F} \cdot \\
& F_{t-1}+D I S C_{-} V B_{r o w, t}+N K G_{-} O N F A_{r o w, t}
\end{aligned}
$$

And it must be the case that:

$\sum N K G_{i}=0$

so that one variable can be obtained as a residual (redundant) from the accounting identity.

\section{A2.1.3 Tracking Capital Incomes}

One of the most powerful tools of SFC models lies in their ability to deal with real-financial connections. This means linking the assets in the balance sheets to the flows of capital income that, added to incomes from production (or, for corporations, profits), forms the primary income $(Y P)$ of the institutional sectors. 
In our model, we have four kinds of incomes from capital. These are divided into income from interest (earned on banks deposits, loans and debt instruments, government bills, and foreign liabilities), income from dividends (for both shares of domestic firms and banks, and the ones related to FDI) and finally, the last two (which only involve model accounting) are other net capital incomes (KYNET) and net rent from land ownership (RENTLN).

While for most interest rates we can choose the appropriate measure, we cannot use a single published rate for the baskets representing foreign liabilities and equities of banks and firms, so we compute the ex post returns as follows ${ }^{43}$ :

$$
\begin{aligned}
& r_{t}^{f}={ }^{I N T P_{\text {row }, t} / F_{t-1}} \\
& r_{t}^{e n}={ }^{D I V P_{n f c, t} / E N_{t-1}} \\
& r_{t}^{e b}={ }^{D I V P_{f c, t}} / E B_{t-1}
\end{aligned}
$$

Next, we need to compute income and payment flows related to the central bank and deduct them from the total receipts and payments of the financial sector. We start by computing interest income received by the $\mathrm{BoI}$ as the sum of receipts on government bonds, foreign liabilities, and ECB advances:

$$
I N T R_{c b}=\left(r_{t}^{a d v} \cdot A D V_{t-1}+r_{t}^{b} \cdot B_{c b, t-1}+r_{t}^{f} \cdot F_{c b, t-1}\right)
$$

We assume ${ }^{44}$ that the central bank does not retain any of this interest income, which is in fact completely disbursed as $O T C_{-} P_{c b}$ to the government sector and subtracted from the total outlays of financial firms by setting $N E T L E N D_{c b}$ equal to zero.

We now have all the ingredients we need to compute the capital income flows for all our sectors. However, when accumulating the relevant income streams for the different sectors one notices the emergence of new discrepancies between the constructed variables and the published ones, which we will model as exogenous and add them to the relative accounting identity.

\footnotetext{
${ }^{43}$ Recall that flow variables are not annualized, so they must be multiplied by four when building stock-flow ratios.

${ }^{44}$ In line with the Statute of BoI.
} 